\title{
Precise Synthesis of Block Polymers Composed of Three or More Blocks by Specially Designed Linking Methodologies in Conjunction with Living Anionic Polymerization System
}

\author{
Yuri Matsuo ${ }^{1}$, Ryuji Konno ${ }^{1}$, Takashi Ishizone ${ }^{1}$, Raita Goseki ${ }^{1}$ and Akira Hirao ${ }^{1,2, *}$ \\ 1 Polymeric and Organic Materials Department, Graduate School of Science and Engineering, \\ Tokyo Institute of Technology, 2-12-1, Ohokayama, Meguro-ku, Tokyo 152-8552, Japan; \\ E-Mails: ymatsuo@polymer.titech.ac.jp (Y.M.); rkonno@polymer.titech.ac.jp (R.K.); \\ tishizon@polymer.titech.ac.jp (T.I.); rgoseki@polymer.titech.ac.jp (R.G.) \\ 2 Institute of Polymer Science and Engineering, National Taiwan University, No.1, Sec.4, \\ Roosevelt Road, Taipei 10617, Taiwan \\ * Author to whom correspondence should be addressed; E-Mail: ahirao@ntu.edu.tw; \\ Tel.: +886-2-2363-8398; Fax: +886-2-2362-3040.
}

Received: 27 May 2013; in revised form: 27 June 2013 / Accepted: 28 June 2013 /

Published: 17 July 2013

\begin{abstract}
This article reviews the successful development of two specially designed linking methodologies in conjunction with a living anionic polymerization system for the synthesis of novel multiblock polymers, composed of three or more blocks, difficult to be synthesized by sequential polymerization. The first methodology with the use of a new heterofunctional linking agent, 2-(4-chloromethylphenyl)ethyldimethylchlorosilane (1), was developed for the synthesis of multiblock polymers containing poly(dimethylsiloxane) (PDMS) blocks. This methodology is based on the selective reaction of the chain-end silanolate anion of living PDMS, with the silyl chloride function of $\mathbf{1}$, and subsequent linking reaction of the resulting $\omega$-chain-end-benzyl chloride-functionalized polymer with either a living anionic polymer or living anionic block copolymer. With this methodology, various multiblock polymers containing PDMS blocks, up to the pentablock quintopolymer, were successfully synthesized. The second methodology using an $\alpha$-phenylacrylate (PA) reaction site was developed for the synthesis of multiblock polymers composed of all-vinyl polymer blocks. In this methodology, an $\alpha$-chain-end-PA-functionalized polymer or block copolymer, via the living anionic polymerization, was first prepared and, then, reacted with appropriate living anionic polymer or block copolymer to link the two polymer chains. As
\end{abstract}


a result, $\mathrm{ACB}(\mathrm{BCA}), \mathrm{BAC}(\mathrm{CAB}),(\mathrm{AB})_{n},(\mathrm{AC})_{n}, \mathrm{ABA}, \mathrm{ACA}, \mathrm{BCB}$, and $\mathrm{ABCA}$ multiblock polymers, where $\mathrm{A}, \mathrm{B}$, and $\mathrm{C}$ were polystyrene, poly(2-vinylpyridine), and poly(methyl methacrylate) segments, could be successfully synthesized. The synthesis of triblock copolymers, $\mathrm{BAB}, \mathrm{CAC}$, and $\mathrm{CBC}$, having molecular asymmetry in both side blocks, was also achieved. Furthermore, the use of living anionic polymers, derived from many other monomers, categorized as either of styrene, 2-vinylpyridine, or methyl methacrylate in monomer reactivity, in the linking methodology enabled the number of synthetically possible block polymers to be greatly increased. Once again, all of the block polymers synthesized by these methodologies are new and cannot be synthesized at all by sequential polymerization. They were well-defined in block architecture and precisely controlled in block segment.

Keywords: anionic polymerization; block polymer; linking methodology; $\alpha$-phenyl acrylate reaction site; benzyl chloride reaction site; multiblock polymer

\section{Abbreviations}

acetal-DIMA

$\alpha \mathrm{MS}$

$\mathrm{BnCl}$

D3

DPE

FMMA

HIC

$\mathrm{P}($ acetal-DIMA)

P(DIMA)

\section{(2,3-dimethyl-1,3-dioxolane-4-yl)methyl} methacrylate

$\alpha$-methylstyrene

benzyl chloride

hexamethylcyclosiloxane

1,1-diphenylethylene

ferrocenylmethyl methacrylate

hexyl isocyanate

poly[(2,3-dimethyl-1,3-dioxolane-4yl)methyl methacrylate]

poly(2,3-dihydroxypropyl methacrylate)

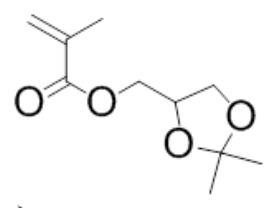<smiles>C=C(C)c1ccccc1</smiles><smiles>ClCc1ccccc1</smiles><smiles>C[Si]1(C)O[Si](C)(C)O[Si](C)(C)O1</smiles><smiles>C=C(c1ccccc1)c1ccccc1</smiles><smiles>C=C(C)C(=O)OCC1CCCC1C1CCCC1</smiles>

$\mathrm{O}=\mathrm{C}=\mathrm{N}-\mathrm{C}_{6} \mathrm{H}_{13}$<smiles>CC1(C)OCC(COC(=O)C(C)(C)C)O1</smiles>

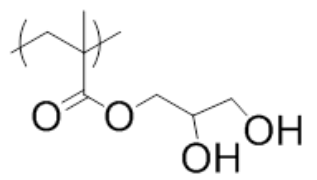




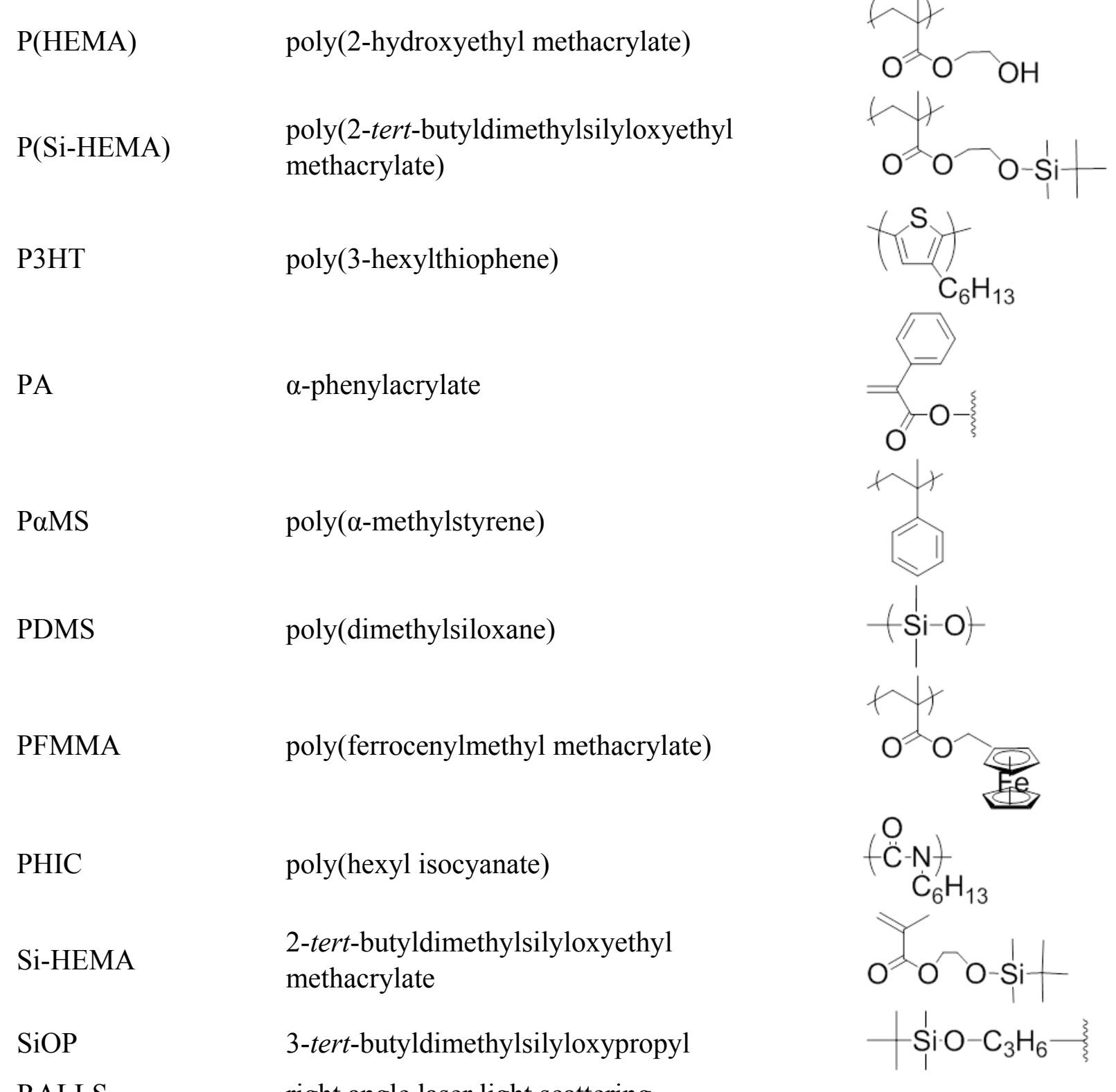

\section{Introduction}

The recent development of living polymerization systems has allowed the successful synthesis of a variety of architectural polymers, such as block polymers, graft polymers, star-branched polymers, and hyperbranched polymers. Among them, block polymers have been the most widely investigated for a long time from the viewpoints of synthesis, properties, behavior, and morphology in solution, bulk, and melt states, as well as practical applications [1-21]. Since block segments are generally thermodynamically incompatible, they are phase-separated at the molecular level, followed by self-organizing to assemble, to form three-dimensional periodic nanostructures and supramolecular assemblies. Such self-assemblies have attracted considerable attention due to the ability to arrange functional domains at the nanoscale, which are expected to play an important role in molecular devices with many potential applications in the fields of nanoscience and nanotechnology. Most block 
polymers utilized for this purpose are currently limited to AB-type diblock copolymers. Although both $\mathrm{ABA}$ and $\mathrm{BAB}$ triblock, and $(\mathrm{AB})_{n}$ alternate multiblock copolymers have been also synthesized and their morphological parameters are similar to those of $\mathrm{AB}$ diblock copolymers, such block copolymers show unique and interesting morphologies, different from those produced from $\mathrm{AB}$ diblock copolymers. Recently, novel characteristic and complicated morphological behavior has been observed in three-component $\mathrm{ABC}$ triblock terpolymers because many variables originated from the three components such as Flory parameters between $\mathrm{A}-\mathrm{B}, \mathrm{B}-\mathrm{C}$, and $\mathrm{C}-\mathrm{A}$ interfaces and the unit numbers of $\mathrm{A}, \mathrm{B}$, and $\mathrm{C}$ segments must be considered [8,22-27].

As a matter of fact, well-defined block polymers with a high degree of molecular and compositional homogeneity are very important to elucidate their basic properties, behavior, and morphologies. In order to synthesize such well-defined block polymers, the use of a living polymerization system is essential. Although various living polymerization systems via different mechanisms have been developed, particularly in the last 25 years, the living anionic polymerization of certain monomers such as styrene, 1,3-butadiene, isoprene, 2-vinylpyridine, and alkyl methacrylates are so far the best living polymerization systems from the view point of the following features: First, molecular weights can be precisely controlled in a wide range, from $10^{3}$ to even $10^{6} \mathrm{~g} / \mathrm{mol}$. Second, extremely narrow molecular weight distributions are attained, $M_{\mathrm{w}} / M_{\mathrm{n}}$ values being 1.05 or even smaller. Third, the tolerance of various functional groups, much more than the numbers that one can consider, can be realized, although some of them are required to be protected during polymerization [28-33]. Finally, the resulting living anionic polymers have active chain-end anions that are highly reactive, but stable under appropriate conditions. These characteristics are ideally suited for the synthesis of well-defined block polymers. In fact, most of well-defined AB diblock copolymers, two-component tri- and alternate multiblock copolymers, and even ABC triblock terpolymers, have been so far synthesized by using this living anionic polymerization system where the corresponding monomers are sequentially added to the anionic initiators, known as "sequential polymerization".

A further consideration for molecular design and precise synthesis of block polymers is the order of monomer addition in sequential polymerization. There is no limitation to the addition order in polymerization using monomers with similar reactivities, and any monomer pair and addition order are acceptable to synthesize almost all possible block polymers. In contrast, the number of block polymers to be synthesized is significantly limited in sequential polymerization using monomers with different reactivities, as the nucleophilicity of the living polymer chain-end anion does not match the electrophilicity of the other monomer, in certain cases. In fact, difficulty often arises in block polymer synthesis by sequential polymerization using monomers with different reactivities. This is recognized as a long-standing problem to be overcome.

In this article, we report on the successful development of specially designed linking methodologies, in conjunction with the living anionic polymerization system for block polymer synthesis in order to overcome the long-standing problem and realize the facile synthesis of synthetically difficult block polymers. Herein, we focus on multiblock polymers composed of three or more block segments, but not diblock copolymers. 


\section{Synthesis of Block Polymers by Sequential Polymerization}

As mentioned in the introduction, well-defined block polymers are generally synthesized by living anionic polymerization, where two or more monomers are sequentially added to an anionic initiator, known as "sequential polymerization". With the use of monomers with similar reactivities, the resulting living polymer chain-end anions also exhibit similar reactivities to each other and thereby crossover polymerization is possible among such monomers. As a result, almost all block polymers can be synthesized. For example, the following three monomers, styrene, 1,3-butadiene, and isoprene, are similar in reactivity. If styrene and 1,3-butadiene are used, both $\mathrm{AB}$ and $\mathrm{BA}$ diblock copolymers of polystyrene (PS)- $b$-poly(1,3-butadiene) (PB) and PB- $b$-PS are readily synthesized by the sequential addition of styrene and 1,3-butadiene, or 1,3-butadiene first, followed by styrene. The synthesis of triblock copolymers of ABA and BAB types, PS- $b$-PB- $b$-PS and PB- $b$-PS- $b$-PB, as well as (AB) alternate multiblock copolymers of (PS- $b-\mathrm{PB})_{n}$ are possible by the same sequential polymerization, where the two monomers are, in turn added, in sequential order based on the structure of the block polymer. With the use of three monomers, styrene, 1,3-butadiene, and isoprene, the sequential addition of these monomers in this order to sec-BuLi results in the formation of an $\mathrm{ABC}$ triblock terpolymer of PS- $b$-PB- $b$-polyisoprene (PI). Two other triblock terpolymers of ACB and BAC types, PS- $b$-PI- $b$-PB and PB- $b$-PS- $b$-PI, are synthesized by changing the addition order of the three monomers. Among the three structurally different methacrylate monomers with similar reactivities, the above-mentioned block polymer synthesis is also possible without problem. In practice, $\mathrm{ABC}, \mathrm{ACB}$, and $\mathrm{BAC}$ triblock terpolymers were successfully synthesized from the following three methacrylate monomers: tert-butyl methacrylate, 2-trimethylsilyloxyethyl methacrylate, and 2-(4-perfluorobutyl)ethyl methacrylate [34,35]. Treatment of poly(2-trimethylsilyloxyethyl methacrylate) with $0.1 \mathrm{~N} \mathrm{HCl}$ quantitatively yielded poly(2-hydroxyethyl methacrylate) having a hydroxyl group in each monomer unit. Thus, interestingly, hydrophilic, hydrophobic, and oleophobic blocks are incorporated and arranged in different sequential order in these triblock terpolymers.

As mentioned above, a significant limitation to block polymer synthesis is encountered by sequential polymerization using monomers with different reactivities [1]. Let us consider block polymer synthesis using three monomers, a, b, and $\mathbf{c}$. The living anionic polymers derived from $\mathbf{a}, \mathbf{b}$, and $\mathbf{c}$ are abbreviated as $\mathrm{A}^{-}, \mathrm{B}^{-}$, and $\mathrm{C}^{-}$, respectively. The three monomers are different in reactivity and assumed to increase in reactivity from $\mathbf{a}$ to $\mathbf{b}$ to $\mathbf{c}$, that is, $\mathbf{a}<\mathbf{b}<\mathbf{c}$. In such a case, the living polymer chain-end anions should be reduced in anionic reactivity from $\mathrm{A}^{-}$to $\mathrm{B}^{-}$to $\mathrm{C}^{-}$, that is, $\mathrm{A}^{-}>\mathrm{B}^{-}>\mathrm{C}^{-}$ as the living polymer chain-end anions are the conjugated bases of the corresponding monomers. When $\mathbf{a}$ is polymerized with an appropriate anionic initiator, a living polymer, $\mathrm{A}^{-}$, is produced. Since $\mathrm{A}^{-}$is the most reactive living polymer among $\mathrm{A}^{-}, \mathrm{B}^{-}$, and $\mathrm{C}^{-}$, the more reactive $\mathbf{b}$ and $\mathbf{c}$ are readily polymerized with $\mathrm{A}^{-}$to give the two living diblock copolymers of $\mathrm{AB}^{-}$and $\mathrm{AC}^{-}$. The $\mathrm{AB}^{-}$can further initiate the polymerization of the most reactive $\mathbf{c}$ to result in a living triblock terpolymer of $\mathrm{ABC}^{-}$, while the least reactive $\mathrm{AC}^{-}$cannot polymerize the less reactive monomer $\mathbf{b}$ having medium reactivity between a and c. Accordingly, an AC diblock copolymer is recovered in this case. Monomer $\mathbf{b}$ is polymerized to produce a living polymer, $\mathrm{B}^{-}$, and $\mathbf{a}$ or $\mathbf{c}$ is added to $\mathrm{B}^{-}$. The $\mathrm{B}^{-}$, having reactivity between $\mathrm{A}^{-}$and $\mathrm{C}^{-}$, cannot polymerize the least reactive monomer $\mathbf{a}$, but can polymerize the most reactive monomer $\mathbf{c}$ to afford a living diblock copolymer of $\mathrm{BC}^{-}$. When the least reactive monomer a 
is added to the resulting $\mathrm{BC}^{-}$, no more polymerization occurs. Finally, $\mathbf{c}$ is polymerized to produce a living polymer, $\mathrm{C}^{-}$. The $\mathrm{C}^{-}$is the least reactive living polymer and is incapable of polymerizing either $\mathbf{a}$ or $\mathbf{b}$, which are less reactive monomers than $\mathbf{c}$. Such reactivity relationships among monomers and their chain-end anions are summarized in Table 1.

Table 1. Reactivity relationships among monomers and their chain-end anions.

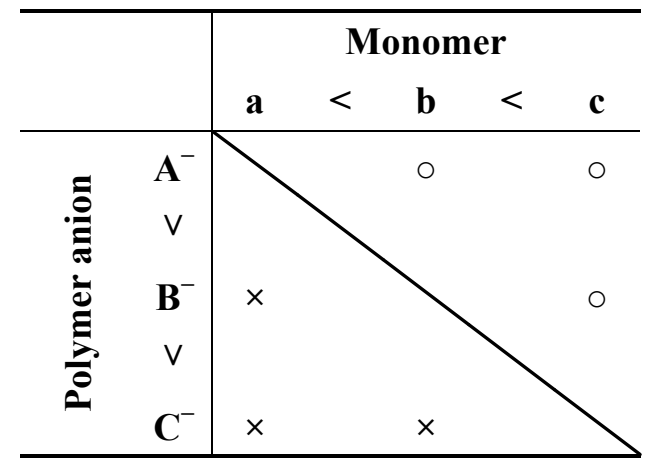

Notes: ○: living polymerization; $\times$ : no polymerization.

Overall, three diblock copolymers of $\mathrm{AB}, \mathrm{AC}$, and $\mathrm{BC}$, as well as one triblock terpolymer of $\mathrm{ABC}$ can be synthesized by sequential polymerization using three monomers with different reactivities. Unfortunately, diblock copolymers of BA, CA, and $\mathrm{CB}$ as well as two triblock terpolymers of ACB, and $\mathrm{BAC}$ cannot be synthesized due to the reactivity difference among living polymer chain-end anions and their monomers. However, BA, CA, and $\mathrm{CB}$ diblock copolymers are the same in block sequence as $\mathrm{AB}, \mathrm{AC}$, and $\mathrm{BC}$ diblock copolymers, although the sequential order is opposite in each case. Accordingly, there is no difference or limitation to diblock copolymer synthesis among sequential polymerizations using monomers with similar and different reactivities. On the other hand, a significant limitation was encountered in triblock terpolymer synthesis by sequential polymerization using monomers with different reactivities. Only synthesis of the ABC type among the three triblock terpolymers is possible; both $\mathrm{ACB}$ and $\mathrm{BAC}$ cannot be obtained by the same polymerization process, even with different addition orders.

What of the synthetic situation of triblock copolymers and alternate multiblock copolymers? With the use of three monomers, the synthesis of six triblock copolymers (ABA, BAB, ACA, CAC, BCB, and $\mathrm{CBC}$ ) can be considered. None of the triblock copolymers shown above can be synthesized at all by sequential polymerization using three monomers with different reactivities, as is estimated from the reactivities of the monomers and chain-end anions shown in Table 1 . The living polymer $\mathrm{B}^{-}$cannot polymerize the least reactive monomer $\mathbf{a}$ and the least reactive $\mathrm{C}^{-}$is not capable of polymerizing $\mathbf{a}$ and $\mathbf{b}$. For the same reason, the synthesis of multiblock copolymers of $(\mathrm{AB})_{n},(\mathrm{AC})_{n}$, and $(\mathrm{BC})_{n}$ types is not possible. Moreover, other multiblock polymers, such as $\mathrm{ABCA}, \mathrm{ABCB}, \mathrm{BACA},(\mathrm{ABC})_{n}$, and so on, also cannot be synthesized.

Table 2 summarizes the synthetic possibilities of block polymers by sequential polymerization using monomers with similar and different reactivities. As can be seen, there is a serious problem in the synthesis of triblock polymers, multiblock polymers with more than four blocks, and alternate multiblock polymers. Almost all block polymers, except for the ABC triblock terpolymer, cannot be 
synthesized by sequential polymerization using monomers with different reactivities, while they can all be obtained by sequential polymerization using monomers with similar reactivities.

Table 2. Synthetic possibilities of block polymers by sequential polymerization using monomers with similar and different reactivities.

\begin{tabular}{cccc}
\hline \multirow{2}{*}{ Type of block polymers } & \begin{tabular}{c} 
Monomers \\
\cline { 3 - 4 }
\end{tabular} & $\begin{array}{c}\text { Similar reactivities } \\
\mathbf{a}=\mathbf{b}=\mathbf{c}\end{array}$ & $\begin{array}{c}\text { Different reactivities } \\
\mathbf{a}<\mathbf{b}<\mathbf{c}\end{array}$ \\
\hline diblock copolymer & $\mathrm{AB}, \mathrm{AC}, \mathrm{BC}$ & 0 & 0 \\
\hline \multirow{2}{*}{ triblock copolymer } & $\mathrm{ABA}, \mathrm{ACA}, \mathrm{BCB}$ \\
$\mathrm{BAB}, \mathrm{CAC}, \mathrm{CBC}$ & 0 & $\times$ \\
\hline multiblock copolymer & $(\mathrm{AB})_{n},(\mathrm{AC})_{n},(\mathrm{BC})_{n}$ & 0 & $\times$ \\
\hline triblock terpolymer & $\mathrm{ABC}, \mathrm{ACB}, \mathrm{BAC}$ & 0 & only $\mathrm{ABC}$ is possible \\
\hline \multirow{2}{*}{ multiblock terpolymer } & $\mathrm{ABCA}, \mathrm{ABCB}, \mathrm{CABC}$ \\
$(\mathrm{ABC})_{n}$ & 0 & $\times$ \\
\hline
\end{tabular}

Notes: $\odot$ : possible; $\times$ : not possible.

Nevertheless, several interesting triblock terpolymers and multiblock polymers with more than four blocks were synthesized by sequential polymerization using monomers with different reactivities. Stadler and Giebeler reported the first successful synthesis of an $\mathrm{ABC}$ triblock terpolymer, PS- $b$-P2VP- $b$-P ${ }^{t}$ BMA [36]. The synthesis was achieved by the sequential addition of styrene, 2VP, and ${ }^{\mathrm{t}} \mathrm{BMA}$ to sec-BuLi. 1,1-Diphenylethylene (DPE) was added to end-cap the chain-end anion of living P2VP prior to the polymerization of ${ }^{t} \mathrm{BMA}$ with a living diblock copolymer of PS- $b$-P2VP in order to prevent the undesirable addition of a chain-end anion to the carbonyl group of ${ }^{t}$ BMA.

Soon after, Müller and his coworkers synthesized a series of the same well-defined triblock terpolymers with different compositions in a similar manner $\left(M_{\mathrm{n}}=72-140 \mathrm{~kg} / \mathrm{mol}\right.$ and $\left.M_{\mathrm{w}} / M_{\mathrm{n}}=1.02-1.04\right)$ [37]. By using these polymers, they established a ternary phase diagram together with anticipated phase-separated structures. The results are very interesting. For example, by decreasing the ${ }^{t} \mathrm{BMA}$ volume fraction, the morphologies change from core-shell cylinders (a PS core surrounded by a P2VP shell in a P'BMA matrix) via a core-shell gyroid in coexistence with a metastable perforated lamellar phase to a lamellar structure. In this sequence, the curvature of the PS/P2VP interface decreases systematically from a cylinder core to a gyroid core to lamellar phase. Further reduction of the P ${ }^{t} \mathrm{BMA}$ block leads to yet another gyroid structure.

Hydrolysis of the $\mathrm{P}^{\mathrm{t}} \mathrm{BMA}$ block with $\mathrm{HCl}$ yielded a new $\mathrm{ABC}$ triblock terpolymer of PS- $b$-P2VP- $b$-poly(methacrylic acid), which exhibited pH-dependent solution properties. An intermolecular complexation of the $\mathrm{P} 2 \mathrm{VP}$ and poly(methacrylic acid) blocks in micellar solution was observed [36].

A variety of functional triblock terpolymers was also synthesized by the same research group. In such triblock terpolymers, they employed three different structural monomers, two of which are similar in reactivity, but different in reactivity from the third monomer. A triblock terpolymer of PS- $b$-PB- $b$-P ${ }^{t} \mathrm{BMA}$ was an example of this type, which was synthesized by the sequential addition of styrene, 1,3-butadiene, and ${ }^{t} \mathrm{BMA}$ to $\sec$-BuLi [38]. Since styrene is similar in reactivity to 1,3-butadiene, another sequentially different triblock terpolymer of PB- $b$-PS- $b$-P ${ }^{t}$ BMA may be synthesized by changing the addition order 
of styrene and 1,3-butadiene. Furthermore, the following triblock terpolymers, belonging to the same category, were also synthesized by means of the same sequential polymerization technique with a careful monomer addition order: Poly(4-tert-butoxystyrene)- $b$-PB- $b$-P ${ }^{t}$ BMA [39], Poly[(5- $N, N$-dimethylamino) isoprene]- $b$-PS- $b$-P ${ }^{t} \mathrm{BMA}$ [40], PB- $b$ - $\mathrm{P}^{t} \mathrm{BMA}-b$-Poly(2-dimethylaminoethyl methacrylate) [41], and PS- $b$-Poly(2-trimethhylsilyloxyethyl methacrylate)- $b$-PMMA [42].

The synthesis of multiblock polymers having more than four blocks by sequential polymerization was reported by Hadjichristidis and his coworkers, as illustrated in Scheme 1. The first synthetic example was an ABCD tetrablock quaterpolymer of PS- $b$-PI- $b$-P2VP- $b$-poly(ethylene oxide) (PEO), which was synthesized by the sequential addition of styrene, isoprene, 2VP, and EO to benzyl potassium as the initiator [43]. The polymerizations of the first three monomers were carried out in THF at $-78^{\circ} \mathrm{C}$ for 1,1 , and $0.5 \mathrm{~h}$, respectively, while the final polymerization of EO was performed in THF at $50{ }^{\circ} \mathrm{C}$ for five days. Moreover, a particular ABCDE pentablock quintopolymer, PS- $b$-PI- $b$ $\mathrm{P} 2 \mathrm{VP}-b$ - $\mathrm{P}^{\mathrm{t}} \mathrm{BMA}-b$-PEO, could also be synthesized in a similar manner by adding in turn the corresponding five monomers to benzyl potassium in THF. The polymerization conditions were $-78{ }^{\circ} \mathrm{C} / 1 \mathrm{~h},-78{ }^{\circ} \mathrm{C} / 1 \mathrm{~h},-78{ }^{\circ} \mathrm{C} / 0.5 \mathrm{~h},-78{ }^{\circ} \mathrm{C} / 0.5 \mathrm{~h}$, and $50{ }^{\circ} \mathrm{C} / 5$ days. The resulting two polymers exhibited sharp monomodal SEC peaks, without any shoulder or tailing, and possessed predictable $M_{\mathrm{n}}$ values of 223 and $92 \mathrm{~kg} / \mathrm{mol}$ and narrow molecular weight distributions of $M_{\mathrm{w}} / M_{\mathrm{n}}$ values of 1.08 and 1.04, respectively. Their compositions observed by ${ }^{1} \mathrm{H}-\mathrm{NMR}$ were consistent with those calculated from feed ratios. Thus, the resulting tetrablock quaterpolymer and pentablock quintopolymer were well-defined in structure and precisely controlled in chain length. Since the reactivity of each monomer increases in this order, styrene $=$ isoprene $<2 \mathrm{VP}<{ }^{\mathrm{t}} \mathrm{BMA}<\mathrm{EO}$, the choice of monomer addition order is reasonable. As the replacement of styrene by isoprene is acceptable, both PI- $b$-PS- $b$-P2 VP- $b$-PEO and PI- $b$-PS- $b$-P2VP- $b$-P'BMA- $b$-PEO can be synthesized.

Scheme 1. Synthesis of PS- $b$-PI- $b$-P2VP- $b$-PEO tetrablock quaterpolymer and PS- $b$-PI- $b$-P2VP- $b$-P'BMA- $b$-PEO pentablock quintopolymer.
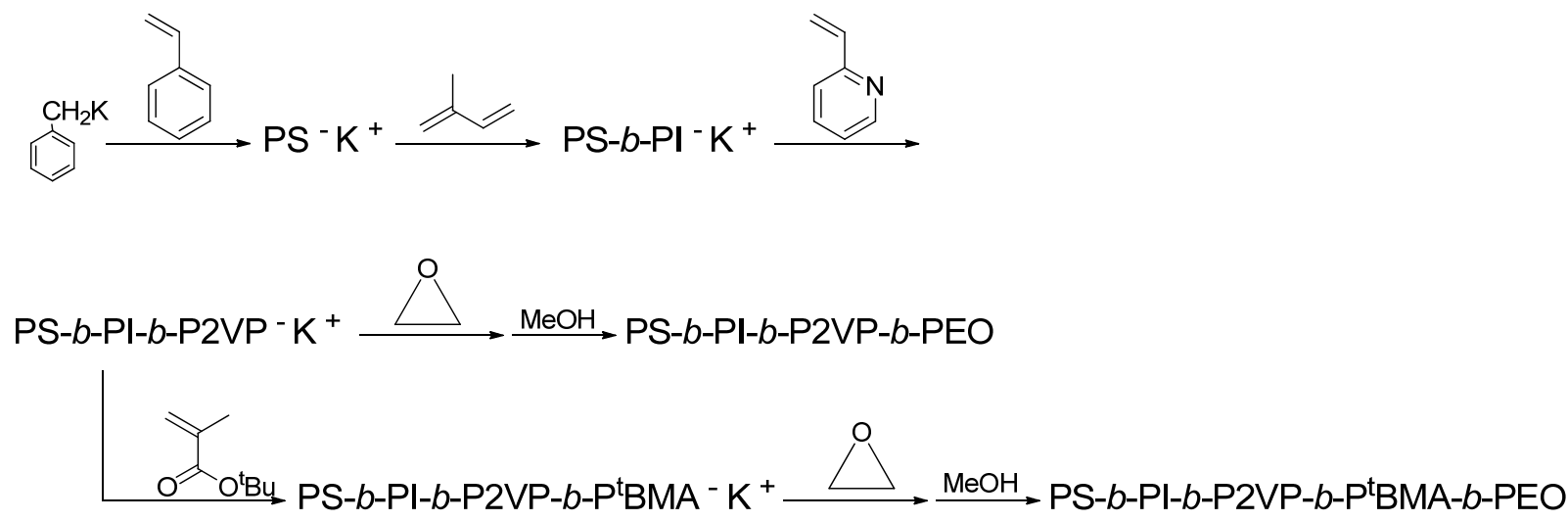

Lee and his coworkers were the first, successful, in achieving the living anionic polymerization of alkyl isocyanate monomers under somewhat special conditions at $-98{ }^{\circ} \mathrm{C}$ with the use of organosodium initiators [41-46]. By using this living polymerization system, Hadjichristidis and his coworkers synthesized a symmetric CBABC pentablock terpolymer, poly(hexyl isocyanate) (PHIC)- $b$-PI- $b$-PS- $b$-PI- $b$-(PHIC) [47]. Since the PHIC block is of special interest in that it adopts an extended rodlike helical conformation either in solution or in bulk, and possesses intriguing properties 
including optical activity and liquid crystalinity, the pentablock terpolymer containing PHIC segments is expected as a new and interesting functional material. The monomer reactivity increases from styrene and isoprene to HIC and, therefore, the order of monomer addition should be styrene, isoprene, followed by HIC in the sequential polymerization. In practice, the objective pentablock terpolymer could be synthesized by the sequential addition of styrene, isoprene, and HIC with sodium naphthalenide used as a difunctional initiator (see Scheme 2). The addition of $\mathrm{NaBPh}_{4}$ to the polymerization system is essential to prevent the undesirable trimerization by a back-biting from the living polymer chain-end anion. The analytical results of two pentablock terpolymers thus synthesized revealed a high degree of molecular and compositional homogeneity, although their molecular weight distributions were relatively broad $\left(M_{\mathrm{n}}=79.4-128 \mathrm{~kg} / \mathrm{mol}, M_{\mathrm{w}} / M_{\mathrm{n}}=1.25-1.32\right)$.

Scheme 2. Synthesis of PHIC- $b$-PI- $b$-PS- $b$-PI- $b$-PHIC pentablock terpolymer.
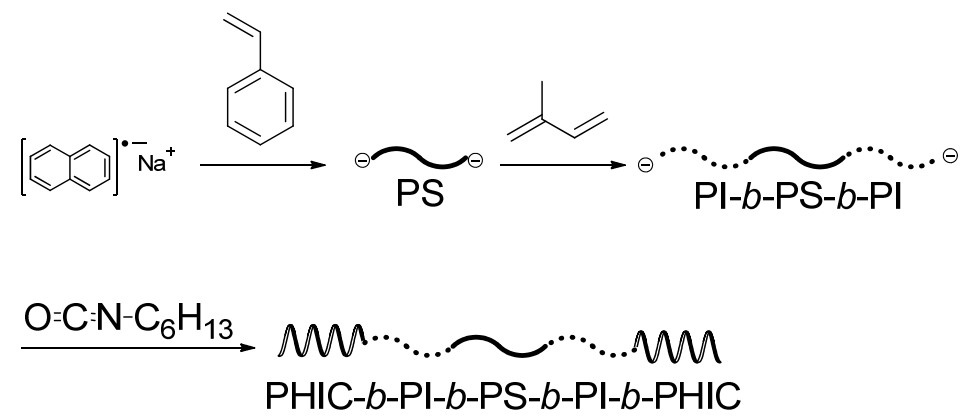

Although certain triblock terpolymers and multiblock polymers, having up to five blocks, could be successfully synthesized by this procedure, their syntheses are still significantly limited by sequential polymerization using monomers with different reactivities. With these limitations and thereby synthetic difficulties in mind, alternative approaches to overcome such problems will be introduced in the next two sections.

\section{Synthesis of Block Polymers by a Linking Methodology Using a Heterofunctional Linking Agent, 2-(4-Chloromethylphenyl)ethyldimethylchlorosilane}

Because of excellent thermal and oxidative stability, high chain flexibility, low glass transition temperature, low surface energy, and low solubility parameter, poly(dimethylsiloxane) (PDMS) is a very important and attractive material in a variety of industrial applications. Furthermore, PDMS is often used in lithographic applications due to its good oxygen reactive ion etching resistance and low absorption in deep UV regions. Consequently, well-defined block polymers containing PDMS segments are of special interest in offering high-performance specialty materials.

The living anionic polymerization of hexamethylcyclosiloxane $\left(\mathrm{D}_{3}\right)$ is undoubtedly the best procedure to obtain well-defined (PDMS)s, but it is not an easy matter to control the polymerization of $\mathrm{D}_{3}$. The living anionic polymerization of $\mathrm{D}_{3}$ has recently been much advanced by Hadjichristidis and his coworkers, with special care to well control the polymerization. Highly reactive living anionic polymers of styrene and isoprene initiate the polymerization of $\mathrm{D}_{3}$ to afford well-defined $\mathrm{AB}$ diblock copolymers of PS- $b$-PDMS and PI- $b$-PDMS [48]. It was also reported that an BAB triblock copolymer of PDMS- $b$-poly(4-vinylpyridine) (P4VP)- $b$-PDMS could be synthesized by sequential polymerization 
of $4 \mathrm{VP}$ and $\mathrm{D}_{3}$ with difunctional sodium naphthalenide as the initiator [49]. Unfortunately, no detailed characterization of molecular weight distribution was available in this report, but it was almost certain that living P4VP and possibly P2VP could polymerize $\mathrm{D}_{3}$. On the other hand, less reactive living polymers of methyl methacrylate (MMA), ${ }^{\mathrm{t}} \mathrm{BMA}$, and other methacrylate monomers cannot initiate the polymerization of $\mathrm{D}_{3}$ because of their chain-end enolate anions with low nucleophilicities. Accordingly, a block copolymer, for example, $\mathrm{P}^{t} \mathrm{BMA}-b$-PDMS cannot be synthesized by sequential polymerization of ${ }^{t} \mathrm{BMA}$, followed by the addition of $\mathrm{D}_{3}$. More problematic is that a silanolate anion derived from $\mathrm{D}_{3}$ is too low in nucleophilicity to initiate the polymerization of styrene, isoprene, 1,3-butadiene, 2VP, and even alkyl methacrylates. This strongly indicates that the use of $\mathrm{D}_{3}$ in block polymer synthesis is especially limited to the preparation of a first-formed block in the sequence.

Hadjichristidis and his coworkers have developed an effective methodology for the synthesis of block polymers containing PDMS segments. As mentioned above, an AB diblock copolymer of PDMS- $b$-P ${ }^{t}$ BMA could not be synthesized, as the living polymer of DMS was not nucleophilic enough to initiate the polymerization of ${ }^{t}$ BMA. In order to link the two polymer chains, they newly synthesized 2-(4-chloromethylphenyl)ethyldimethylchlorosilane (1) as a heterofunctional linking agent on the basis of the greater reactivity of the silyl chloride than the benzyl chloride $(\mathrm{BnCl})$ function toward the silanolate anion [50]. The reaction sequence for the synthesis of the above diblock copolymer is given in Scheme 3. The living PDMS was first prepared by the anionic polymerization of $\mathrm{D}_{3}$ with sec-BuLi and then reacted with a 1.1-fold excess of 1 . The reaction of the silanolate anion with the silyl chloride function of 1 was observed by ${ }^{1} \mathrm{H}-\mathrm{NMR}$ analysis to be quite selective, while the $\mathrm{BnCl}$ function remained completely intact, resulting in an $\omega$-chain-end-BnCl-functionalized PDMS. Living ${ }^{t} \mathrm{BMA}$ was prepared by the anionic polymerization of ${ }^{t} \mathrm{BMA}$ with 1,1-diphenylhexyllithium in THF in the presence of $\mathrm{LiCl}$ at $-78{ }^{\circ} \mathrm{C}$ and then reacted with the $\omega$-chain-end-BnCl-functionalized PDMS. A two-fold excess of living $\mathrm{P}^{t} \mathrm{BMA}$ toward the $\mathrm{BnCl}$ function was used and the reaction was carried out at $-25{ }^{\circ} \mathrm{C}$ for three days. Unfortunately, only $30 \%$ conversion was obtained under such conditions. Quantitative conversion could be achieved by the addition of a catalytic amount of CsI to transform the chloride into a more reactive iodide. A well-defined PDMS- $b$-P ${ }^{t}$ BMA $\left(M_{\mathrm{n}}=55.3 \mathrm{~kg} / \mathrm{mol}\right.$, $M_{\mathrm{w}} / M_{\mathrm{n}}=1.03$, PDMS $\left.(w / w, \%)=50 \%\right)$ was obtained in $100 \%$ yield. Thus, the linking of PDMS with $\mathrm{P}^{\mathrm{t}} \mathrm{BMA}$, difficult to be linked by sequential polymerization, was successful.

Scheme 3. Synthesis of $\mathrm{P}^{t}$ BMA- $b$-PDMS and P2VP- $b$-PDMS diblock copolymers.
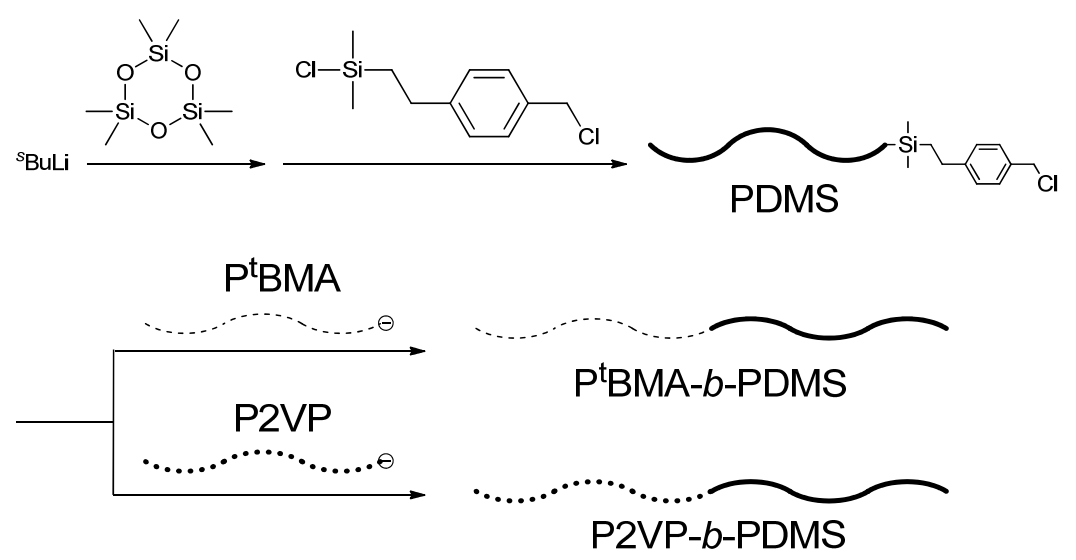
Similarly, it was observed that the linking reaction of living P2VP quantitatively occurred with $\omega$-chain-end-BnCl-functionalized PDMS in the presence of a catalytic amount of CsI even at $-78{ }^{\circ} \mathrm{C}$ to afford a well-defined PDMS- $b$-P2VP $\left(M_{\mathrm{n}}=20.2 \mathrm{~kg} / \mathrm{mol}, M_{\mathrm{w}} / M_{\mathrm{n}}=1.07\right.$, PDMS $\left.(w / w, \%)=20 \%\right)$ (see also Scheme 3). Thus, the agent 1, was also effective to link P2VP with PDMS.

This methodology using $\mathbf{1}$ was extended to synthesize particular multiblock polymers, which cannot be synthesized by sequential polymerization. The first successful example is a tetrablock quaterpolymer of PS- $b$-PI- $b$-PDMS- $b$-P2VP, as illustrated in Scheme 4 [51]. A living triblock terpolymer, PS- $b$-PI- $b$-PDMS, was first prepared by the sequential polymerization of styrene, isoprene, and then $\mathrm{D}_{3}$ with sec-BuLi and subsequently reacted with $\mathbf{1}$ to give an $\omega$-chain-end-BnCl-functionalized PS- $b$-PI- $b$-PDMS. Living P2VP was then reacted with the $\omega$-chain-end-BnCl-functionalized PS- $b$-PI- $b$-PDMS in the presence of a catalytic amount of CsI at $-78{ }^{\circ} \mathrm{C}$ for three days in order to complete the linking reaction. A well-defined and requisite structure of the resulting tetrablock quaterpolymer of PS- $b$-PI- $b$-PDMS- $b$-P2VP, after isolation by fractional precipitation, was confirmed by SEC and ${ }^{1} \mathrm{H}-\mathrm{NMR}$ analyses. Typically, the tetrablock quaterpolymer possessed a predictable $M_{\mathrm{n}}$ value of $98.8 \mathrm{~kg} / \mathrm{mol}$ and a narrow molecular weight distribution, the $M_{\mathrm{w}} / M_{\mathrm{n}}$ value being 1.03 . The composition ( $w / w, \%)$ of PS/PI/PDMS/P2VP was 30.5/25.5/25.3/21.1. Very interestingly, four phases of the microphase-separated structure in this tetrablock quaterpolymer were unequivocally observed. The PI, PDMS, and P2VP microphases formed triple coaxial cylinders with a hexagonal shape packed in a hexagonal arrary in the PS microphase, which formed the honeycomb-shaped matrix.

Scheme 4. Synthesis of PS- $b$-PI- $b$-PDMS- $b$-P2VP tetrablock quaterpolymer.

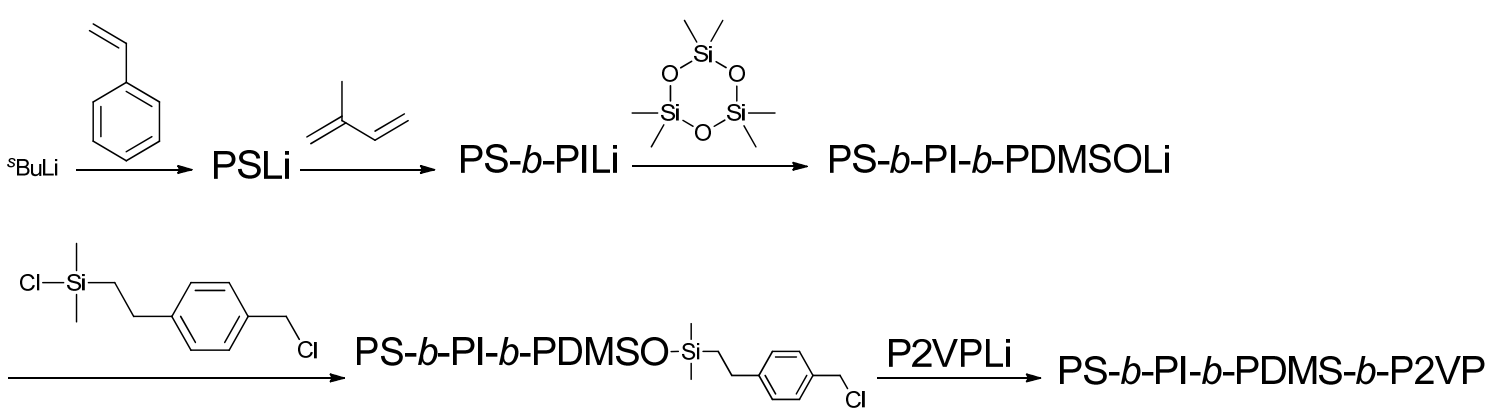

A quite novel pentablock quintopolymer, PS- $b$-PI- $b$-PDMS- $b$-P ${ }^{t}$ BMA- $b$-P2VP, was also successfully synthesized by developing the same linking methodology shown in Scheme 5 [52]. The first step involved the preparation of an $\omega$-chain-end-BnCl-functionalized triblock terpolymer of PS- $b$-PI- $b$-PDMS by the sequential polymerization of styrene, isoprene, and $\mathrm{D}_{3}$ with $s e c-\mathrm{BuLi}$, followed by reacting it with $\mathbf{1}$, in exactly the same manners as those described above. A living diblock copolymer was separately prepared by the polymerization where 2VP and ${ }^{\mathrm{t}} \mathrm{BMA}$ was sequentially polymerized with benzylpotassium and reacted with the $\omega$-chain-end-BnCl-functionalized PS- $b$-PI- $b$-PDMS at $-25{ }^{\circ} \mathrm{C}$ for three days. In this linking reaction, a two-fold excess of living diblock copolymer of P2VP- $b-\mathrm{P}^{\mathrm{t}} \mathrm{BMA}$ was used for the $\mathrm{BnCl}$ function of the triblock terpolymer and a catalytic amount of $\left(\mathrm{C}_{4} \mathrm{H}_{9}\right)_{4} \mathrm{NI}$ was added to replace the chloride with the more reactive iodide to complete the reaction. Under such conditions, the linking reaction was observed to quantitatively take place to link the two block polymer chains. Thus, the target pentablock quintopolymer, PS- $b$-PI- $b$-PDMS- $b$-P BMA- $b$-P2VP, was successfully synthesized. A series of pentablock quintopolymers with different compositions could 
also be synthesized by changing the feed ratios. A high degree of molecular and compositional homogeneity was clearly exhibited in each of all block polymers, as listed in Table 3.

Scheme 5. Synthesis of PS- $b$-PI- $b$-PDMS- $b-P^{t}$ BMA- $b$-P2VP pentablock quintopolymer.

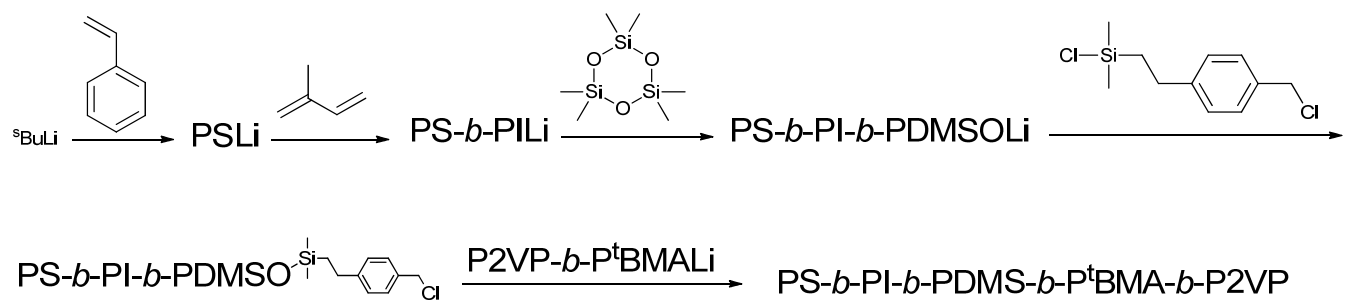

The synthesis by this linking methodology is based on both the advanced living anionic polymerization of $\mathrm{D}_{3}$ and the selective linking reaction of the silanolate anion with the silyl chloride function of $\mathbf{1}$. With this methodology, a series of well-defined block polymers containing PDMS segments from diblock to even quite novel pentablock types have been successfully synthesized. Thus, the methodology using 1 herein developed becomes a very effective and versatile procedure for the synthesis of block polymers containing PDMS segments.

Table 3. Molecular characteristics of poly(dimethylsiloxane) (PDMS) containing block polymers.

\begin{tabular}{cccc}
\hline Sample & $\boldsymbol{M}_{\mathbf{n}} \times \mathbf{1 0}^{-\mathbf{3}}(\mathbf{g} / \mathbf{m o l})$ & $\boldsymbol{M}_{\mathbf{w}} / \boldsymbol{M}_{\mathbf{n}}$ & Composition $^{\mathrm{e}}(\boldsymbol{\%} \boldsymbol{w} / \boldsymbol{w})$ \\
\hline PDMS- $b$-P BMA & $55.3^{\mathrm{a}}$ & $1.02^{\mathrm{c}}$ & $51 / 49$ \\
PDMS- $b$-P2VP & $20.2^{\mathrm{a}}$ & $1.07^{\mathrm{c}}$ & $20 / 80$ \\
PS- $b$-PI- $b$-PDMS- $b$-P2VP & $155.4^{\mathrm{a}}$ & $1.04^{\mathrm{d}}$ & $52 / 18 / 12 / 18$ \\
PS- $b$-PI- $b$-PDMS- $b$-P BMA- $b$-P2VP & $161.4^{\mathrm{b}}$ & $1.05^{\mathrm{b}}$ & $20 / 9 / 17 / 25 / 29$ \\
\hline
\end{tabular}

Notes: ${ }^{a}$ Membrane osmometry in toluene at $37{ }^{\circ} \mathrm{C}$; ${ }^{b}$ Size exclusion chromatography, SEC-two angle laser detector, in $\mathrm{CHCl}_{3} / \mathrm{TEA}(95 / 5 \mathrm{v} / \mathrm{v})$ at $35{ }^{\circ} \mathrm{C}$; ${ }^{\mathrm{c}} \mathrm{SEC}$ in THF at $25{ }^{\circ} \mathrm{C}$; ${ }^{\mathrm{d}} \mathrm{SEC}$ in $\mathrm{CHCl}_{3}$ at $25{ }^{\circ} \mathrm{C}$; ${ }^{1} \mathrm{H}-\mathrm{NMR}$ at $25{ }^{\circ} \mathrm{C}$.

\section{Synthesis of Block Polymers by a Linking Methodology Using an $\alpha$-Phenylacrylate Linking Reaction Site}

\subsection{Triblock Copolymers and Alternate Multiblock Copolymers}

In the preceding section, it was reported that the heterofunctional agent, 1, effectively worked in the synthesis of multiblock polymers containing PDMS segments. However, this agent is not so effective for the linking of two living polymer chains derived from vinyl monomers, since two linking sites, the silyl chloride and the $\mathrm{BnCl}$ functions, cannot be selectively reacted for typical living anionic polymers of vinyl monomers. It is also disadvantageous that the formation of an unstable $\mathrm{Si}-\mathrm{O}$ bond is formed in the linking reaction between the silyl chloride function and the living polymer of MMA or other alkyl methacrylate monomers. These synthetic problems have been overcome by developing a new alternative linking methodology using an $\alpha$-phenylacrylate linking reaction site [53-58].

As can be seen in Table 1, a and $\mathbf{c}$ typically correspond to styrene and MMA, respectively. Living PS initiates the polymerization of MMA to afford a well-defined diblock copolymer of PS- $b$-PMMA, while no polymerization of styrene takes place at all with living PMMA. This means that not only a 
triblock copolymer of PS- $b$-PMMA- $b$-PS, but also PMMA- $b$-PS- $b$-PMMA cannot be synthesized by sequential polymerization for the same reason. As a matter of fact, the synthesis of a tetrablock copolymer of PS- $b$-PMMA- $b$-PS- $b$-PMMA, a pentablock copolymer of PS- $b$-PMMA- $b$-PS- $b$-PMMA- $b$-PS, and so on, to (PS- $b$-PMMA) ${ }_{n}$ multiblock copolymers is not possible. In order to synthesize these block copolymers, we have developed a new alternative linking methodology, as illustrated in Scheme $6[59,60]$.

Scheme 6. Synthesis of (a) PS- $b$-PMMA- $b$-PS and (b) PMMA- $b$-PS- $b$-PMMA triblock copolymers.

(a)

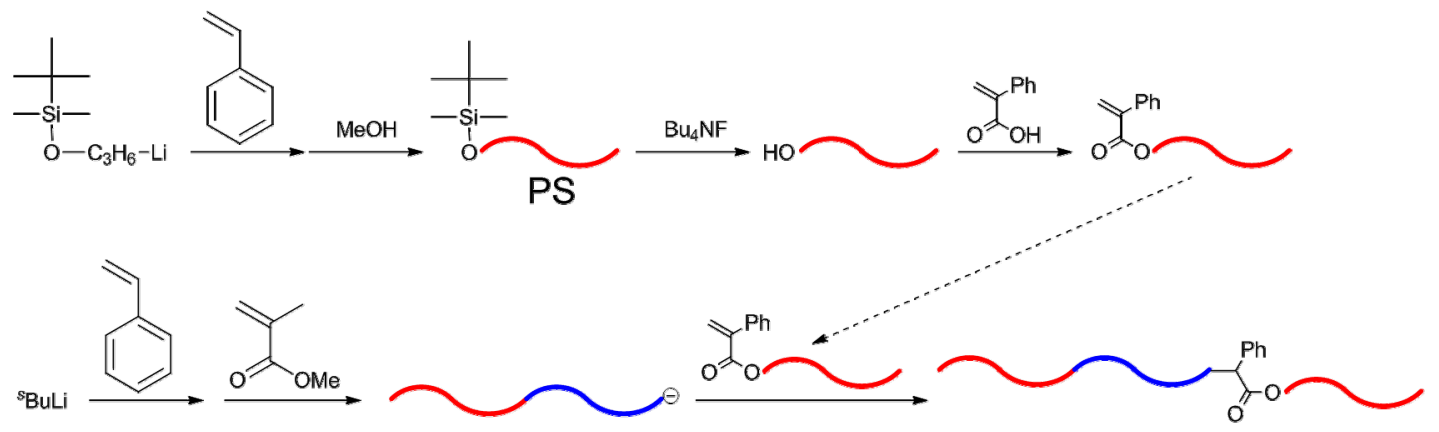

PS-b-PMMA

PS- $b$-PMMA- $b$-PS

(b)

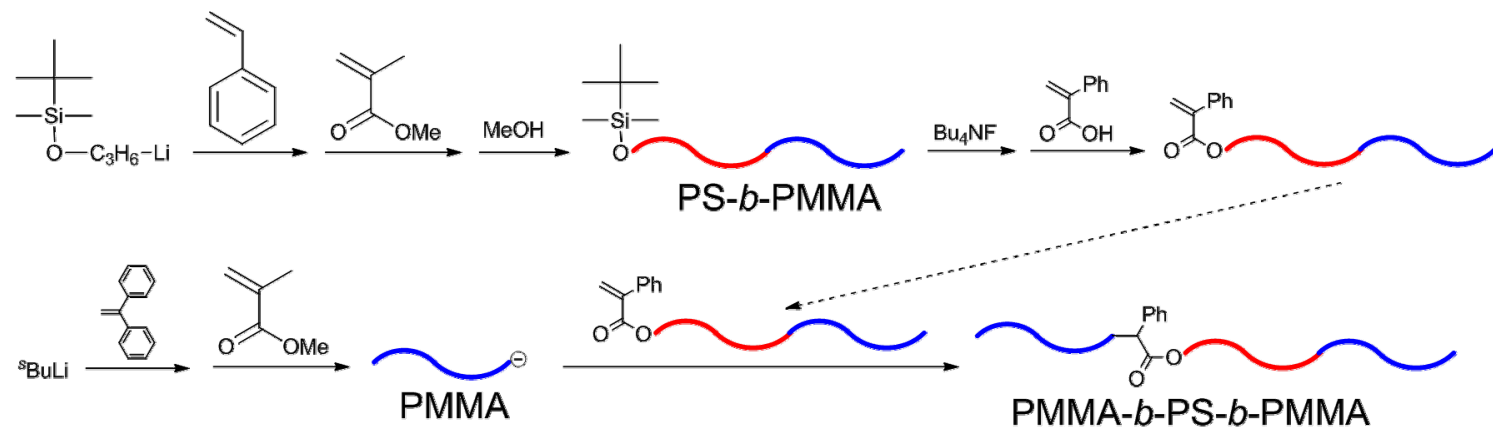

For the synthesis of a triblock copolymer, PS- $b$-PMMA- $b$-PS, styrene was first polymerized with 3-(tert-butyldimethylsilyloxy)-1-propyllithium (SiOPLi) in a living manner to afford an $\alpha$-chain-end-(3-tert-butyldimethylsilyloxypropyl) (SiOP)-functionalized PS. The $\alpha$-terminal SiOP group was converted to an $\alpha$-phenylacrylate (PA) function by treatment with $\left(\mathrm{C}_{4} \mathrm{H}_{9}\right)_{4} \mathrm{NF}$, followed by esterification with $\alpha$-phenylacrylic acid under the Mitsunobu reaction conditions using diisopropyl azodicarboxylate and $\mathrm{Ph}_{3} \mathrm{P}$. The esterification was quantitative under the conditions with a 20-fold excess or more of $\alpha$-phenylacrylic acid, resulting in an $\alpha$-chain-end-PA-functionalized PS. A living diblock copolymer, PS- $b$-PMMA, was separately prepared by the sequential addition of styrene, DPE, and MMA to sec-BuLi and reacted with $\alpha$-chain-end-PA-functionalized PS in THF at $-40{ }^{\circ} \mathrm{C}$ for $20 \mathrm{~h}$. DPE was used to end-cap the living PS to prevent an addition reaction to the carbonyl group of MMA. A three-fold excess of the living diblock copolymer for the PA function was employed based of our knowledge [58]. The reaction proceeded cleanly and completely, under such conditions, to link the PMMA chain with the PS segment, which could not be linked by sequential polymerization. As the resulting product was mixture of target-linked polymer, and excess used PS- $b$-PMMA, isolation was required. As a result, a new well-defined PS- $b$-PMMA- $b$-PS triblock copolymer was successfully obtained in 54\% isolated yield. Other block copolymers described below were also isolated from the excess used polymer after the linking reaction. 
For the synthesis of a PMMA- $b$-PS- $b$-PMMA triblock copolymer, as also shown in Scheme 6, an $\alpha$-chain-end-PA-functionalized PS- $b$-PMMA instead of an $\alpha$-chain-end-PA-functionalized PS was used. It was prepared by the sequential polymerization of styrene and MMA with SiOPLi in a similar manner to that mentioned above, followed by deprotection of the silyl group with $\left(\mathrm{C}_{4} \mathrm{H}_{9}\right)_{4} \mathrm{NF}$ and subsequent esterification with $\alpha$-phenylacrylic acid. Then, living PMMA was prepared by the anionic polymerization of MMA with 1,1-diphenyl-3-methylpentyllithium in the presence of a five-fold excess of $\mathrm{LiCl}$ and reacted with the $\alpha$-chain-end-PA-functionalized PS- $b$-PMMA at $-40{ }^{\circ} \mathrm{C}$ for $20 \mathrm{~h}$. In this case, a three-fold excess of living PMMA for the PA function was used to complete the reaction. The quantitative linking of the PMMA chain with the PS segment was again successful under the conditions employed. It is thus possible to synthesize both triblock copolymers, PS- $b$-PMMA- $b$-PS as well as PMMA- $b$-PS- $b$-PMMA, by combining the linking reaction using the $\alpha$-phenylacrylate reaction site with living anionic polymers and block polymers. Needless to say, both block copolymers cannot be synthesized by the sequential polymerization using styrene and MMA. Similarly, both triblock copolymers of PS- $b$-P2VP- $b$-PS [59] and P2VP- $b$-PS- $b$-P2VP [60] were successfully synthesized by the same linking methodology and either living P2VP or living diblock copolymers of PS- $b$-P2VP.

Among the above block copolymers, PMMA- $b$-PS- $b$-PMMA and P2VP- $b$-PS- $b$-P2VP can also be synthesized by the sequential polymerization of styrene and either MMA or 2VP with a certain difunctional initiator. In these block copolymers, the PMMA or P2VP side blocks always become equal to each other in molecular weight and it is not possible to make the molecular weight different. With the linking methodology herein developed, one side block can be changed in molecular weight to that of the other side block. For example, the linking reaction of living PMMA $\left(M_{\mathrm{n}}=18.7 \mathrm{~kg} / \mathrm{mol}\right)$ with $\alpha$-chain-end-PA-functionalized PS- $b$-PMMA $\left(M_{\mathrm{n}}=11.2 / 11.6 \mathrm{~kg} / \mathrm{mol}\right)$ enables one to synthesize a triblock copolymer of PMMA- $b$-PS- $b$-PMMA $\left(M_{\mathrm{n}}=18.7 / 11.2 / 11.6 \mathrm{~kg} / \mathrm{mol}, M_{\mathrm{w}} / M_{\mathrm{n}}=1.03\right)$, in which the PMMA side blocks are different in molecular weight. Two more asymmetric triblock copolymers, P2VP- $b$-PS- $b$-P2VP $\left(M_{\mathrm{n}}=19.5 / 10.0 / 10.4 \mathrm{~kg} / \mathrm{mol}, M_{\mathrm{w}} / M_{\mathrm{n}}=1.02\right)$ and PMMA- $b$-P2VP- $b$-PMMA $\left(M_{\mathrm{n}}=6.30 / 12.6 / 20.5 \mathrm{~kg} / \mathrm{mol}, M_{\mathrm{w}} / M_{\mathrm{n}}=1.03\right)$, could also be synthesized. Thus, the linking methodology allows access to such special triblock copolymers with molecular asymmetry in the side blocks. This is an additional advantage in the linking methodology developed in this section.

This methodology was extended to the synthesis of a series of alternate multiblock copolymers of (PS- $b$-PMMA $)_{n}$ [61]. The synthetic outline is shown in Scheme 7. For such multiblock copolymer synthesis, the $\alpha$-chain-end-SiOP-functionalized living diblock copolymer of PS- $b$-PMMA was always employed as a building block and prepared by procedures similar to those mentioned above. The resulting block copolymer was converted to the $\alpha$-chain-end-PA-functionalized PS- $b$-PMMA in the same manner. Again, the $\alpha$-chain-end-SiOP-functionalized living PS- $b$-PMMA was prepared and reacted with the $\alpha$-chain-end-PA-functionalized PS- $b$-PMMA under identical conditions. The reaction quantitatively proceeded to link the two block copolymer chains, resulting in a tetrablock copolymer of PS- $b$-PMMA- $b$-PS- $b$-PMMA. Since the resulting tetrablock copolymer still possessed the SiOP function at the $\alpha$-terminus, the same reaction sequence could be repeated three more times to successfully synthesize a hexablock copolymer, PS- $b$-PMMA- $b$-PS- $b$-PMMA- $b$-PS- $b$-PMMA, an octablock copolymer, PS- $b$-PMMA- $b$-PS- $b$-PMMA- $b$-PS- $b$-PMMA- $b$-PS- $b$-PMMA, and even a decablock copolymer, PS- $b$-PMMA- $b$-PS- $b$-PMMA- $b$-PS- $b$-PMMA- $b$-PS- $b$-PMMA- $b$-PS- $b$-PMMA in essentially $100 \%$ yield. Each of all polymers exhibits a sharp monomodal SEC distribution and 
moves to high molecular weight regions by increasing the PS- $b$-PMMA unit, as shown in Figure 1. The well-defined and requisite structures of the resulting multiblock copolymers have all been confirmed by excellent agreement of the calculated $M_{\mathrm{n}}$ values and those observed by SEC-RALLS, and the narrowness of the molecular weight distributions, as summarized in Table 4. The success of block copolymer synthesis from triblock to alternate multiblock polymers (even a decablock type) is strongly attributed to the use of a PA function capable of quantitative linking with an even less reactive living PMMA chain-end enolate anion.

Scheme 7. Synthesis of (PS- $b$-PMMA $)_{n}$ alternate multiblock copolymers.
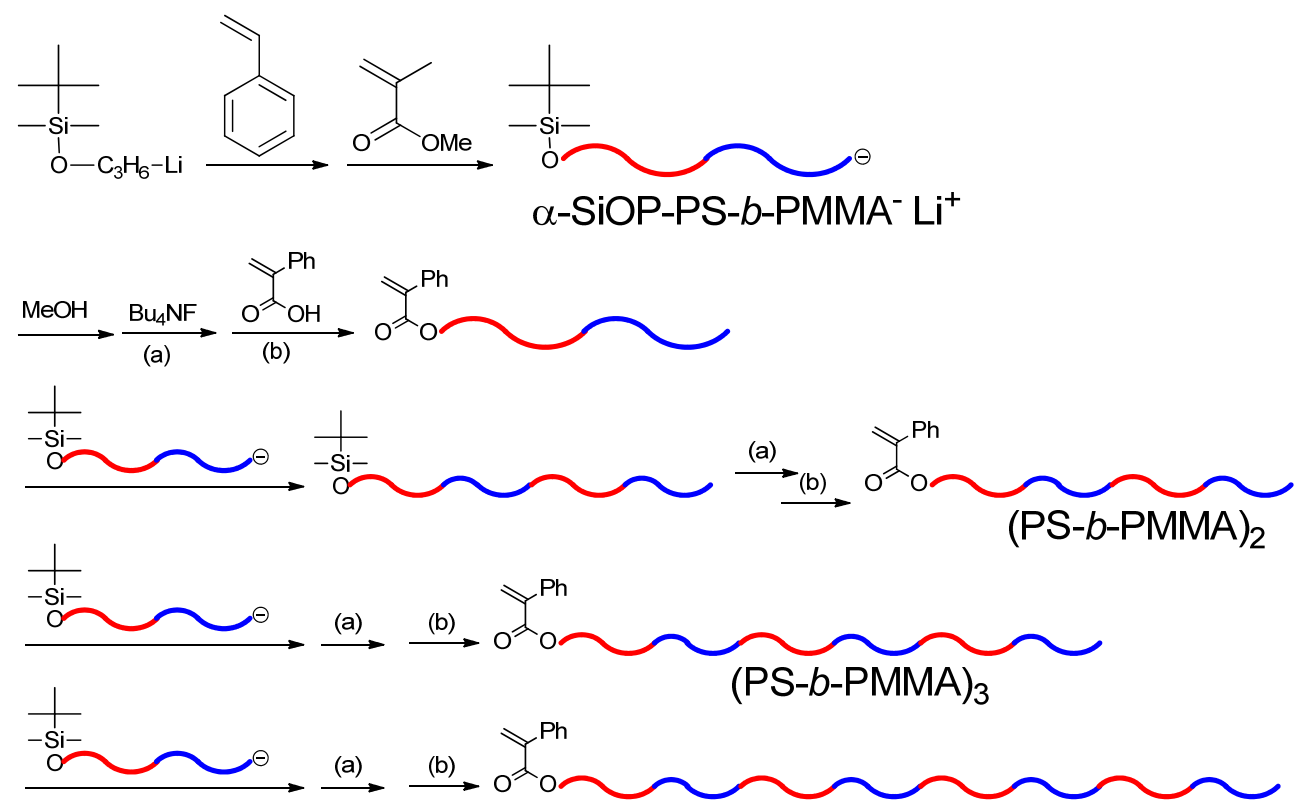

$(\mathrm{PS}-b-\mathrm{PMMA})_{3}$

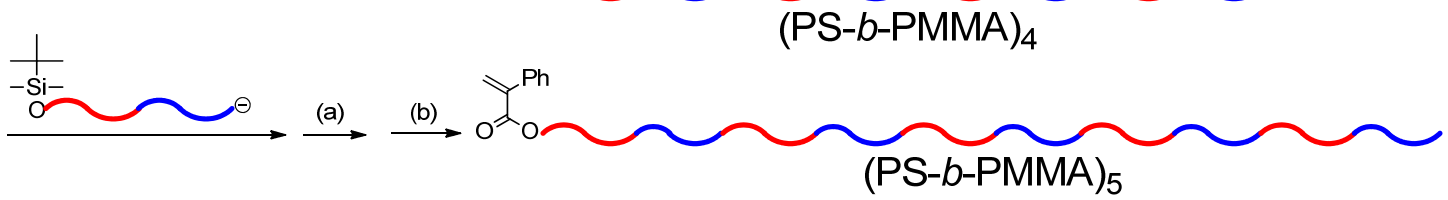

Figure 1. SEC profiles for a series of multiblock copolymers: (a) AB diblock; (b) $(\mathrm{AB})_{2}$ tetrablock; (c) $(\mathrm{AB})_{3}$ hexablock; (d) $(\mathrm{AB})_{4}$ octablock; and (e) $(\mathrm{AB})_{5}$ decablock copolymers.

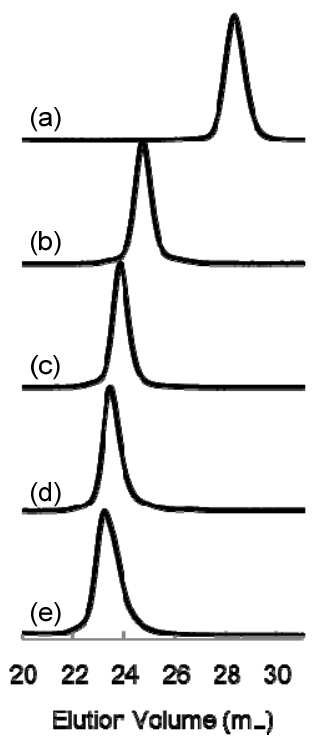


Similarly, tetrablock and hexablock copolymers of PS- $b$ - P $^{t}$ BMA- $b$-PS- $b$ - P $^{t}$ BMA and PS- $b$-P ${ }^{t}$ BMA- $b$-PS- $b$-P ${ }^{t}$ BMA- $b$-PS- $b$-P ${ }^{t}$ BMA were successfully synthesized by developing exactly the same methodology except for the use of an $\alpha$-chain-end-SiOP-functionalized living diblock copolymer of PS- $b$-P ${ }^{t}$ BMA as a building block. These block copolymers may be converted to (PS- $b$-poly(methacrylic acid) $)_{n}(n=2$ and 3$)$ by hydrolysis of the P'BMA block. It is also possible to synthesize tetrablock and hexablock copolymers of PS- $b$-P2VP- $b$-PS- $b$-P2VP and PS- $b$-P2VP- $b$-PS- $b$ P2VP- $b$-PS- $b$-P2VP by using an $a$-chain-end-SiOP-functionalized living diblock copolymer of PS- $b$-P2VP as a building block in the same methodology (see also Table 4). In the linking reaction for the synthesis of (PS- $b$-P2VP) $)_{n}$, the use of a 1.5-fold excess of the living $\alpha$-chain-end-SiOP-functionalized PS- $b$-P2VP in the linking reaction at $-78{ }^{\circ} \mathrm{C}$ for $10 \mathrm{~h}$ was enough to complete the reaction with the $\alpha$-chain-end-PA-functionalized PS- $b$-P2VP. Interestingly, the P2VP block can be readily converted to a water-soluble polyelectrolyte poly(2-vinylpyridinium salt) by treatment with either RX or HX. Thus, synthetically difficult alternate multiblock copolymers composed of PS and PMMA, P'BMA, and P2VP could be synthesized for the first time by developing a linking methodology using the PA reaction site together with living anionic polymers or diblock copolymers.

Table 4. Synthesis of a series of alternate $(\mathrm{AB})_{n}$ multiblock copolymers composed of (A) PS and (B) PMMA, P'BMA, or P2VP blocks.

\begin{tabular}{|c|c|c|c|c|c|c|c|}
\hline \multicolumn{2}{|c|}{ Polymer } & \multirow{2}{*}{ Type } & \multicolumn{2}{|c|}{$M_{\mathrm{n}} \times 10^{-3}(\mathrm{~g} / \mathrm{mol})$} & \multirow{2}{*}{$M_{\mathrm{w}} / M_{\mathrm{n}}^{\mathrm{b}}$} & \multicolumn{2}{|c|}{ Composition $(\% w / w)$} \\
\hline A & B & & Calculated & RALLS $^{\text {a }}$ & & Calculated & ${ }^{1}$ H-NMR \\
\hline \multirow{11}{*}{ PS } & \multirow{5}{*}{ PMMA } & $\mathrm{AB}$ & 10.5 & 11.4 & 1.03 & $50 / 50$ & $48 / 52$ \\
\hline & & $\mathrm{ABAB}$ & 26.4 & 28.2 & 1.03 & $48 / 52$ & $47 / 53$ \\
\hline & & $\mathrm{ABABAB}$ & 37.0 & 40.5 & 1.03 & $45 / 55$ & $43 / 57$ \\
\hline & & ABABABAB & 51.0 & 53.6 & 1.04 & $45 / 55$ & $43 / 57$ \\
\hline & & ABABABABAB & 64.5 & 66.4 & 1.06 & $45 / 55$ & $45 / 55$ \\
\hline & \multirow{3}{*}{$\mathrm{P}^{t} \mathrm{BMA}$} & $\mathrm{AB}$ & 10.4 & 13.1 & 1.03 & $47 / 53$ & $46 / 54$ \\
\hline & & $\mathrm{ABAB}$ & 24.0 & 25.8 & 1.03 & $47 / 53$ & $46 / 54$ \\
\hline & & ABABAB & 41.5 & 46.6 & 1.06 & $48 / 52$ & $46 / 54$ \\
\hline & \multirow{3}{*}{ P2VP } & $\mathrm{AB}$ & 11.3 & 12.7 & 1.04 & $52 / 48$ & $50 / 50$ \\
\hline & & $\mathrm{ABAB}$ & 24.3 & 25.3 & 1.04 & $49 / 51$ & $49 / 51$ \\
\hline & & ABABAB & 37.2 & 38.3 & 1.03 & $49 / 51$ & $48 / 52$ \\
\hline
\end{tabular}

Notes: ${ }^{a}$ Determined by SEC equipped with triple detectors; ${ }^{\mathrm{b}}$ Estimated by SEC with standard polystyrene.

\subsection{Triblock Terpolymers Using Three Monomers with Different Reactivities}

As often mentioned, an $\mathrm{ABC}$ triblock terpolymer is the only triblock terpolymer to be synthesized by sequential polymerization using three monomers with different reactivities, while the synthesis of two other triblock terpolymers of ACB and BAC types are not possible because the living AC diblock copolymer and living B polymer cannot initiate the polymerization of the $\mathbf{b}$ and $\mathbf{a}$, respectively (see Table 1). As is also seen in Table 1, in the case where $\mathbf{a}, \mathbf{b}$, and $\mathbf{c}$ correspond to styrene, $2 \mathrm{VP}$, and MMA (similar to ${ }^{\mathrm{t}} \mathrm{BMA}$ in reactivity), the ABC triblock terpolymer, PS- $b$-P2VP- $b$-PMMA, was actually synthesized by the sequential addition of these three monomers, similar to the synthesis of the PS- $b$-P2VP- $b-\mathrm{P}^{t} \mathrm{BMA}$ triblock terpolymer previously reported. 
Synthetically difficult $\mathrm{ACB}$ and BAC triblock terpolymers by sequential polymerization, PS- $b$-PMMA- $b$-P2VP and P2VP- $b$-PS- $b$-PMMA, were synthesized by extending the linking methodology developed in the preceding section. The reaction sequences are given in Scheme 8 [59]. In the synthesis of PS- $b$-PMMA- $b$-P2VP (ACB), an $\alpha$-chain-end-PA-functionalized P2VP was first prepared by the polymerization of $2 \mathrm{VP}$ with the initiator from sec-BuLi and 1-(3-tert-butyldimethylsilyloxymethylphenyl)-1-phenylethylene, followed by deprotection with $\left(\mathrm{C}_{4} \mathrm{H}_{9}\right)_{4} \mathrm{NF}$ and subsequent esterification with $\alpha$-phenylacrylic acid, and then reacted with a three-fold excess of a living diblock copolymer of PS- $b$-PMMA at $-40{ }^{\circ} \mathrm{C}$ for $20 \mathrm{~h}$. The reaction cleanly and quantitatively proceeded under such conditions to link the PS- $b$-PMMA block with P2VP chain, resulting in the target triblock terpolymer. Similarly, P2VP- $b$-PS- $b$-PMMA (BAC) was synthesized by the linking reaction of a 1.5 -fold excess of living P2VP with the $\alpha$-chain-end-PA-functionalized PS- $b$-PMMA at $-78^{\circ} \mathrm{C}$ for $10 \mathrm{~h}$ (see also Scheme 8 ).

Scheme 8. Synthesis of (a) PS- $b$-PMMA- $b$-P2VP and (b) P2VP- $b$-PS- $b$-PMMA triblock terpolymers.

(a)

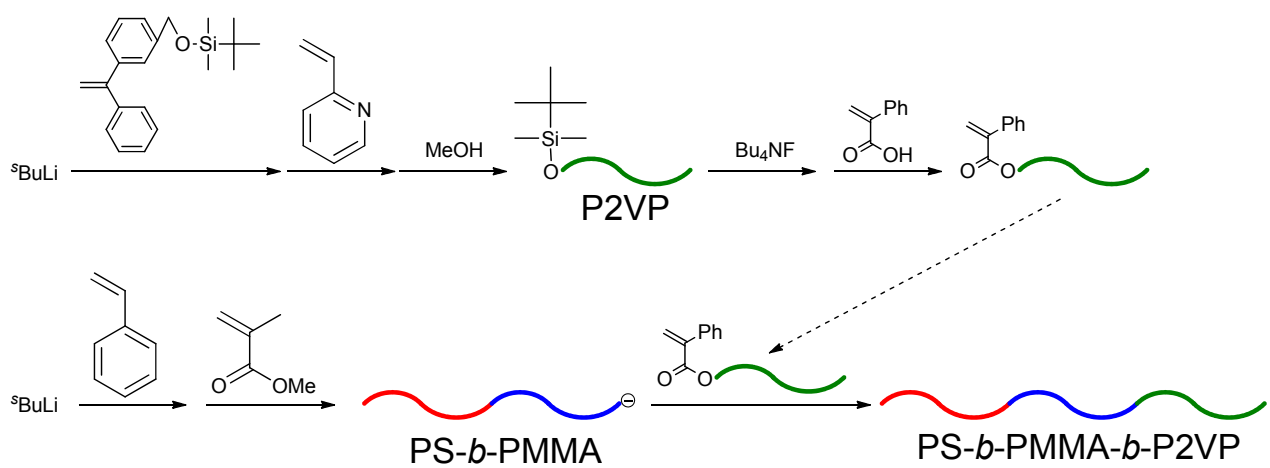

(b)

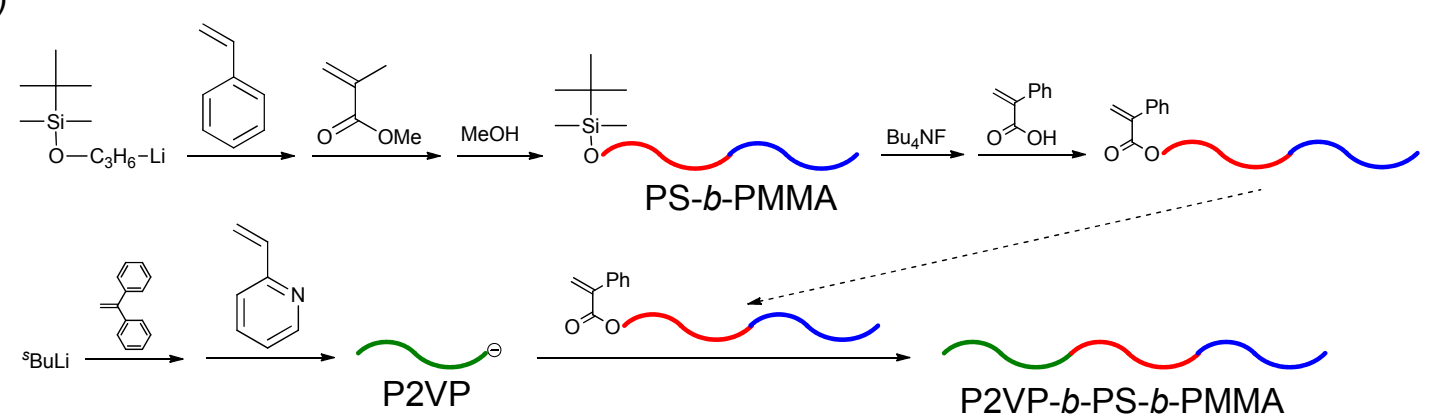

The two triblock terpolymers, P2VP- $b$-PMMA- $b$-PS (BCA) and PMMA- $b$-PS- $b$-P2VP (CAB), are the same in block sequence as the above two polymers of PS- $b$-PMMA- $b$-P2VP (ACB) and P2VP- $b$-PS- $b$-PMMA (BAC), although the sequential order is exactly opposite in each triblock terpolymer. Very advantageously, different molecular designs are usable in the linking reaction for the synthesis of such structurally same triblock terpolymers. For example, the synthesis of P2VP- $b$-PMMA- $b$-PS (BCA) was achieved by the linking reaction of a three-fold excess of living diblock copolymer of P2VP- $b$-PMMA with an $\alpha$-chain-end-PA-functionalized PS in THF at $-40{ }^{\circ} \mathrm{C}$ for $20 \mathrm{~h}$. One more triblock terpolymer, PMMA- $b$-PS- $b$-P2VP (CAB), was synthesized by linking living PMMA with an $\alpha$-chain-end-PA-functionalized PS- $b$-P2VP under the same conditions as those 
used above. Thus, two synthetic routes are available for each triblock terpolymer. Their well-defined structures are confirmed by the good agreement of $M_{\mathrm{n}}$ values and compositions as well as narrow molecular weight distributions, as listed in Table 5. Thus, the methodology based on the linking reaction using the PA reaction site with living anionic polymers and block polymers is also very effective for the synthesis of triblock terpolymers which cannot be synthesized by sequential polymerization.

Table 5. Molecular characteristics of $\mathrm{ACB}(\mathrm{BCA})$ and BAC (CAB) triblock terpolymers.

\begin{tabular}{|c|c|c|c|c|c|c|c|}
\hline \multirow{2}{*}{ Type } & \multirow{2}{*}{ Living polymer } & \multirow{2}{*}{$\begin{array}{l}\text { PA-Functionalized } \\
\text { polymer }\end{array}$} & \multicolumn{2}{|c|}{$M_{\mathrm{n}} \times 10^{-3}(\mathrm{~g} / \mathrm{mol})$} & \multirow{2}{*}{$M_{\mathrm{w}} / M_{\mathrm{n}} \mathrm{b}^{-}$} & \multicolumn{2}{|c|}{ Composition $(\% w / w)$} \\
\hline & & & $\begin{array}{l}\text { Calculated } \\
\end{array}$ & RALLS $^{a}$ & & Calculated & ${ }^{1}$ H-NMR \\
\hline ACB & PS- $b$ & $\alpha \mathrm{PA}-\mathrm{P} 2 \mathrm{VP}$ & 32.2 & 34.6 & 1.04 & $25 / 58 / 17$ & $27 / 54 / 19$ \\
\hline $\mathrm{BCA}$ & $\mathrm{P}^{\mathrm{VP}}-b-\mathrm{PMMA}^{-}$ & $\alpha \mathrm{PA}-\mathrm{PS}$ & 28.9 & 30.1 & 1.05 & $32 / 34 / 34$ & $31 / 34 / 35$ \\
\hline $\mathrm{BAC}$ & $\mathrm{P}^{2} \mathrm{VP}^{-}$ & $\alpha \mathrm{PA}-\mathrm{PS}-b$-PMMA & 37.2 & 38.2 & 1.04 & $32 / 35 / 33$ & $31 / 37 / 32$ \\
\hline $\mathrm{CAB}$ & $\mathrm{PMMA}^{-}$ & $\alpha \mathrm{PA}-\mathrm{PS}-b-\mathrm{P} 2 \mathrm{VP}$ & 34.0 & 34.3 & 1.04 & $31 / 33 / 36$ & $29 / 37 / 34$ \\
\hline
\end{tabular}

Notes: ${ }^{a}$ Determined by SEC equipped with triple detectors; ${ }^{b}$ Estimated by SEC with standard polystyrene.

Once again, a, b, and c correspond to styrene, 2VP, and MMA, respectively, and their polymers are represented as A, B, and C, according to the style shown in Table 1. It is known that a variety of monomers also belongs to either of the three monomers categorized by their different monomer reactivities. Typically, $\alpha$-methylstyrene, 4-methylstyrene, 4-methoxystyrene, 4-tert-butyldimethylsilyloxystyrene and 4-bis(trimethylsilyl)aminostyrene, usable as protected monomers convertible to poly(4-hydroxystyrene) and poly(4-aminostyrene), 1,3-butadiene, and isoprene, are in monomer a category. $4 \mathrm{VP}$ is similar in reactivity to $2 \mathrm{VP}$ of monomer $\mathbf{b}$. Many methacrylate monomers such as ${ }^{\mathrm{t}} \mathrm{BMA}$, allyl methacrylate, benzyl methacrylate, 2-dimethylaminoethyl methacrylate, and ferrocenylmethyl methacrylate are categorized as monomer c based on their reactivities. Moreover, 2-trimethylsilyloxyethyl methacrylate and 2-tert-butyldimethylsilyloxyethyl methacrylate (silyl-protected forms of 2-hydroxyethyl methacrylate) and (2,3-dimethyl-1,3-dioxolan-4-yl)methyl methacrylate (an acetal-protected 2,3-dihydroxypropyl methacrylate) are also similar in reactivity to c. These monomers are listed in Chart 1. With the appropriate use of such monomers in the linking methodology, a huge number of $\mathrm{ACB}$ (or $\mathrm{BCA}$ ) and $\mathrm{BAC}$ (or $\mathrm{CAB}$ ) triblock terpolymers can be synthesized without difficulty.

\subsection{Triblock Terpolymers Using Three Monomers with Two Different Reactivities}

As listed in Chart 1, the three categorized monomers except for (a) styrene, (b) 2VP, and (c) MMA, are abbreviated as $\mathbf{a}^{\prime}, \mathbf{b}^{\prime}$, and $\mathbf{c}^{\prime}$. Since they are similar in monomer reactivity to $\mathbf{a}, \mathbf{b}$, and $\mathbf{c}$, respectively, their reactivities are increased from $\mathbf{a}^{\prime}$ to $\mathbf{b}^{\prime}$ to $\mathbf{c}^{\prime}\left(\mathbf{a}^{\prime}<\mathbf{b}^{\prime}<\mathbf{c}^{\prime}\right)$ and their chain-end anions, $\mathrm{A}^{\prime^{-}}, \mathrm{B}^{\prime^{-}}$, and $\mathrm{C}^{\prime^{-}}$, should decrease in reactivity $\left(\mathrm{A}^{\prime^{-}}>\mathrm{B}^{\prime^{-}}>\mathrm{C}^{\prime^{-}}\right)$. Using three structurally different monomers with two different reactivities, the synthetic possibility of triblock terpolymers of $\mathrm{ABA}^{\prime}$, $\mathrm{ACA}^{\prime}, \mathrm{BAB}^{\prime}, \mathrm{BCB}^{\prime}, \mathrm{CAC}^{\prime}$, and $\mathrm{CBC}^{\prime}$ types is first considered. Typically, $\mathbf{a}^{\prime}$ and $\mathbf{b}^{\prime}$ correspond to $\alpha$-methylstyrene $(\alpha \mathrm{MS})$ and $4 \mathrm{VP}$, while $\mathbf{c}^{\prime}$ is one of the following methacrylate monomers: ${ }^{t} \mathrm{BMA}$, 2-tert-butyldimethylsilyloxyethyl methacrylate (a silyl-protected form of 2-hydroxyethyl methacrylate (Si-HEMA)), 2,3-dimethyl-1,3-dioxolan-4-yl)methyl methacrylate (an acetal-protected form of 2,3-dihydroxypropyl methacrylate (acetal-DIMA)), or ferrocenylmethyl methacrylate (FMMA). The 
above six triblock terpolymers cannot be synthesized by the sequential addition of the corresponding monomers because of a mismatch of their monomer reactivities with those of chain-end anions [60].

Chart 1. Monomers, $\mathbf{a}, \mathbf{b}$, and $\mathbf{c}$ with different reactivities.

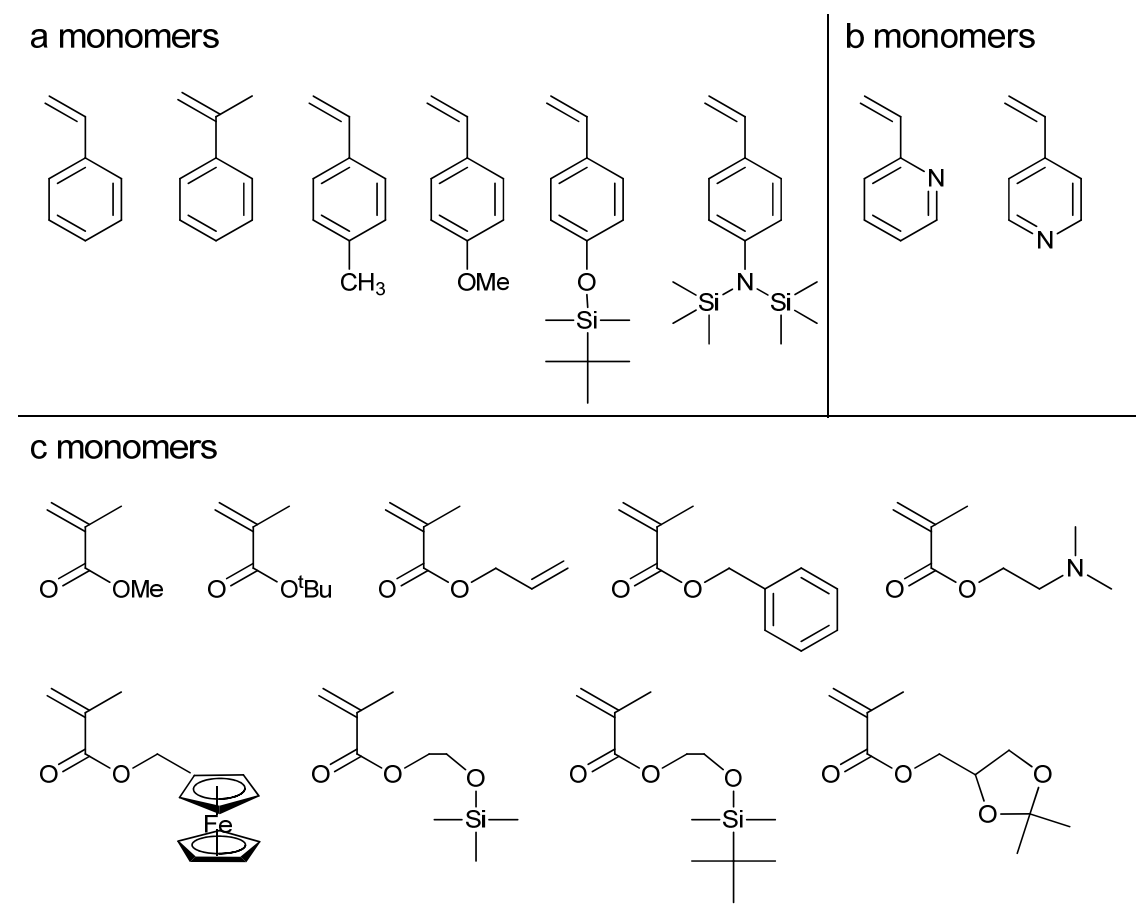

At first, we describe the synthesis of $\mathrm{ABA}^{\prime}$ and $\mathrm{ACA}^{\prime}$ triblock terpolymers, PS- $b$-P2VP- $b$-P $\alpha \mathrm{MS}$ and PS- $b$-PMMA- $b$-P $\alpha$ MS. The ABA' may be synthesized by the linking reaction of a living $\mathrm{AB}$ diblock copolymer with an $\alpha$-chain-end-PA-functionalized $\mathrm{A}^{\prime}$. The $\mathrm{A}^{\prime} \mathrm{BA}$ triblock terpolymer is the same in block structure as the $\mathrm{ABA}^{\prime}$ and may be synthesized by a different combination of a living $\mathrm{A}^{\prime} \mathrm{B}$ diblock copolymer with an $\alpha$-chain-end-PA-functionalized $\mathrm{A}$ in the linking reaction. Similarly, the synthesis of an $\mathrm{ACA}^{\prime}$ (or $\mathrm{A}^{\prime} \mathrm{CA}$ ) triblock terpolymer may be achieved by the linking reaction of a living $\mathrm{AC}$ (or $\mathrm{A}^{\prime} \mathrm{C}$ ) diblock copolymer with an $\alpha$-chain-end-PA-functionalized $\mathrm{A}^{\prime}$ (or $\mathrm{A}$ ). For experimental convenience, both $\mathrm{A}^{\prime} \mathrm{BA}$ and $\mathrm{A}^{\prime} \mathrm{CA}$ polymers were synthesized. A 1.5-fold excess of living P $\alpha$ MS- $b$-P2VP or a three-fold excess of living P $\alpha$ MS- $b$-PMMA block copolymers was used in the reactions with an $\alpha$-chain-end-PA-functionalized PS in THF at $-78^{\circ} \mathrm{C}$ for $10 \mathrm{~h}$ or at $-40{ }^{\circ} \mathrm{C}$ for $20 \mathrm{~h}$. Both linking reactions were observed to proceed virtually quantitatively to afford two polymers with well-defined structures, as listed in Table 6.

Table 6. Molecular characteristics of $\mathrm{A}^{\prime} \mathrm{BA}$ and $\mathrm{A}^{\prime} \mathrm{CA}$ triblock terpolymers.

\begin{tabular}{|c|c|c|c|c|c|}
\hline \multirow{2}{*}{ Sample } & \multicolumn{2}{|c|}{$M_{\mathrm{n}} \times 10^{-3}(\mathrm{~g} / \mathrm{mol})$} & \multirow{2}{*}{$M_{\mathrm{w}} / M_{\mathrm{n}} \mathrm{b}^{-}$} & \multicolumn{2}{|c|}{ Composition $(\% w / w)$} \\
\hline & Calculated & RALLS $^{a}$ & & Calculated & ${ }^{1} \mathrm{H}-\mathrm{NMR}$ \\
\hline $\mathrm{A}^{\prime} \mathrm{BA}(\mathrm{P} \alpha \mathrm{MS}-b-\mathrm{P} 2 \mathrm{VP}-b-\mathrm{PS})$ & 21.0 & 20.6 & 1.05 & $22 / 26 / 52$ & $26 / 31 / 43$ \\
\hline $\mathrm{A}^{\prime} \mathrm{CA}(\mathrm{P} \alpha \mathrm{MS}-b$-PMMA- $b-\mathrm{PS})$ & 20.6 & 20.6 & 1.04 & $21 / 23 / 56$ & $23 / 25 / 52$ \\
\hline
\end{tabular}

Notes: ${ }^{a}$ Determined by SEC equipped with triple detectors; ${ }^{b}$ Estimated by SEC with standard polystyrene.

The BAB' triblock terpolymer, P2VP- $b$-PS- $b$-P4VP, was synthesized by the linking reaction of a two-fold excess of living P2VP with an $\alpha$-chain-end-PA-functionalized PS- $b$-P4VP in THF at $-78{ }^{\circ} \mathrm{C}$ 
for $15 \mathrm{~h}$. In contrast, the attempt to synthesize a P4VP- $b$-PS- $b$-P2VP (B'AB) polymer by the linking reaction of living P4VP with $\alpha$-chain-end-PA-functionalized PS- $b$-P2VP was not successful because the living P4VP used as the $\mathrm{B}^{\prime}$ block precipitated at an early stage of the polymerization in THF at $-78^{\circ} \mathrm{C}$ and the resulting living P4VP was totally insoluble in $\mathrm{THF}$ at $-78^{\circ} \mathrm{C}$. We initially thought that a $\mathrm{BCB}^{\prime}$ (or $\mathrm{B}^{\prime} \mathrm{CB}$ ) triblock terpolymer could be synthesized by linking of a living $\mathrm{BC}$ (or $\mathrm{B}^{\prime} \mathrm{C}$ ) diblock copolymer with an $\alpha$-chain-end-PA-functionalized $\mathrm{B}^{\prime}$ (or $\mathrm{B}$ ). Unfortunately, neither an $\alpha$-chain-end-PA-functionalized P4VP nor a living P4VP- $b$-PMMA could be prepared because of the insolubility of living $\mathrm{P} 4 \mathrm{VP}$ in THF as mentioned above. Thus, the synthesis of $\mathrm{BCB}^{\prime}$ (P2VP- $b$-PMMA-b-P4VP), as well as $\mathrm{B}^{\prime} \mathrm{CB}$ (P4VP-b-PMMA- $b$-P2VP), was not successful. With the use of $\mathrm{P} 4 \mathrm{VP}$ as the $\mathrm{B}^{\prime}$ block, it was possible to synthesize only a $\mathrm{BAB}^{\prime}$ triblock terpolymer among the above four block polymer candidates ( $\mathrm{BAB}^{\prime}, \mathrm{B}^{\prime} \mathrm{AB}, \mathrm{BCB}^{\prime}$, and $\left.\mathrm{B}^{\prime} \mathrm{CB}\right)$.

In the synthesis of $\mathrm{CAC}^{\prime}$ (or $\mathrm{C}^{\prime} \mathrm{AC}$ ) triblock terpolymers, the following four functional methacrylate-based polymers were employed as $\mathrm{C}^{\prime}$ blocks: ${ }^{t} \mathrm{BMA}, \mathrm{P}(\mathrm{Si}-\mathrm{HEMA}), \mathrm{P}$ (acetal-DIMA), and PFMMA. For synthetic convenience, $\mathrm{C}^{\prime} \mathrm{AC}$ triblock terpolymers, instead of the $\mathrm{CAC}^{\prime}$ type, were synthesized because the same $\alpha$-chain-end-PA-functionalized AC diblock copolymer is usable in each case in the linking reaction. A three-fold excess of living $\mathrm{C}^{\prime}$ was reacted in THF at $-40{ }^{\circ} \mathrm{C}$ for $10 \mathrm{~h}$ to go to completion. The linking reaction only with the use of living $\mathrm{P}^{\mathrm{t}} \mathrm{BMA}$ was not sufficient under such conditions, but essentially quantitative by raising the temperature to $-25{ }^{\circ} \mathrm{C}$. All of the resulting triblock terpolymers were well-defined in structure and precisely controlled in block segment, as listed in Table 7.

Table 7. Molecular characteristics of $\mathrm{C}^{\prime} \mathrm{AC}$ and $\mathrm{C}^{\prime} \mathrm{BC}$ triblock terpolymers.

\begin{tabular}{|c|c|c|c|c|c|c|}
\hline & \multirow[t]{2}{*}{ Sample } & \multicolumn{2}{|c|}{$M_{\mathrm{n}} \times 10^{-3}(\mathrm{~g} / \mathrm{mol})$} & \multirow{2}{*}{$M_{\mathrm{w}} / M_{\mathrm{n}}^{\mathrm{b}}$} & \multicolumn{2}{|c|}{ Composition $(\%, w / w)$} \\
\hline & & Calculated & RALLS $^{\text {a }}$ & & Calculated & ${ }^{1}$ H-NMR \\
\hline \multirow{4}{*}{$\mathrm{C}^{\prime} \mathrm{AC}$} & $\mathrm{P}^{t} \mathrm{BMA}-b$-PS- $b$-PMMA & 32.8 & 34.5 & 1.03 & $35 / 31 / 34$ & $35 / 31 / 34$ \\
\hline & P(Si-HEMA)- $b$-PS- $b$-PMMA & 32.5 & 32.4 & 1.04 & $34 / 32 / 34$ & $28 / 35 / 37$ \\
\hline & $\mathrm{P}($ acetal-DIMA)- $b$-PS- $b$-PMMA & 32.0 & 33.3 & 1.03 & $33 / 32 / 35$ & $33 / 33 / 34$ \\
\hline & PFMMA- $b$-PS- $b$-PMMA & 32.5 & 29.1 & 1.03 & $31 / 33 / 36$ & $31 / 33 / 36$ \\
\hline \multirow{3}{*}{$\mathrm{C}^{\prime} \mathrm{BC}$} & $\mathrm{P}^{t} \mathrm{BMA}-b-\mathrm{P} 2 \mathrm{VP}-b$-PMMA & 37.7 & 36.2 & 1.03 & $30 / 27 / 43$ & $33 / 26 / 41$ \\
\hline & $\mathrm{P}$ (acetal-DIMA)- $b$-P2VP- $b$-PMMA & 36.3 & 34.9 & 1.05 & $29 / 28 / 43$ & $26 / 29 / 45$ \\
\hline & PFMMA- $b$-P2VP- $b$-PMMA & 35.1 & 35.4 & 1.04 & $26 / 29 / 45$ & $27 / 29 / 44$ \\
\hline
\end{tabular}

Notes: ${ }^{a}$ Determined by SEC equipped with triple detectors; ${ }^{b}$ Estimated by SEC with standard polystyrene.

Treatment of P(Si-HEMA)- $b$-PS- $b$-PMMA and P(acetal-DIMA)- $b$-PS- $b$-PMMA with $\left(\mathrm{C}_{4} \mathrm{H}_{9}\right)_{4} \mathrm{NF}$ and $0.2 \mathrm{~N} \mathrm{HCl}$, respectively, yielded new and interesting functional triblock terpolymers, PHEMA- $b$ PS- $b$-PMMA and PDIMA- $b$-PS- $b$-PMMA with well-defined structures. P'BMA- $b$-PS- $b$-PMMA could be converted to a poly(methacrylic acid)- $b$-PS- $b$-PMMA, as shown in Scheme 9.

Similarly, any of the three living $C^{\prime}$ s could be linked with the same $\alpha$-chain-end-PA-functionalized $\mathrm{BC}$ to quantitatively afford three different $\mathrm{C}^{\prime} \mathrm{BC}$ triblock terpolymers, ${ }^{t} \mathrm{BMA}-b$-P2VP- $b$-PMMA, P(acetal-DIMA)- $b$-P2VP- $b$-PMMA, and PFMMA- $b$-P2VP- $b$-PMMA. SEC profiles as well as the characterization results, summarized in Table 7 , showed that each linking reaction quantitatively proceeded to result in the target polymers with well-defined structures. Thus, the linking methodology with the PA reaction site also satisfactorily functions for the synthesis of new triblock terpolymers 
represented as $\mathrm{ABA}^{\prime}, \mathrm{ACA}^{\prime}, \mathrm{BAB}^{\prime}, \mathrm{CAC}^{\prime}$, and $\mathrm{CBC}^{\prime}$. Unfortunately, the synthesis of $\mathrm{BCB}^{\prime}$ was not successful due to the insolubility of P4VP chosen as the $\mathrm{B}^{\prime}$ segment. However, the $\mathrm{BCB}^{\prime}$ triblock terpolymer may possibly be synthesized by the appropriate choice of another $\mathrm{B}^{\prime}$ segment soluble in THF, because living polymer $\mathrm{C}$ usually reacts with the terminal PA function.

Scheme 9. Deprotection of (a) P(Si-HEMA); (b) P(acetal-DIMA); and (c) P'BMA blocks.

(a)

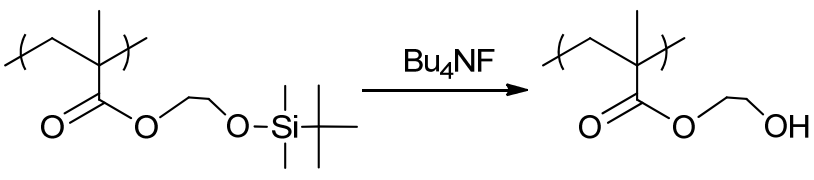

(b)

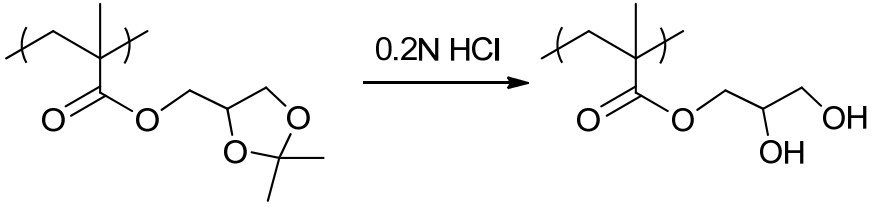

(c)

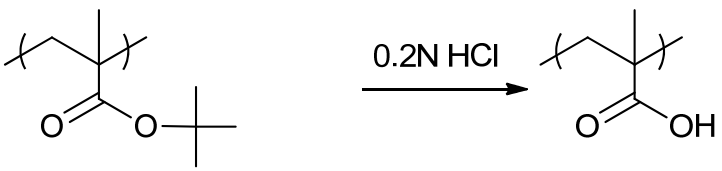

A series of $\mathrm{AB}^{\prime} \mathrm{A}^{\prime}, \mathrm{AC}^{\prime} \mathrm{A}^{\prime}, \mathrm{BA}^{\prime} \mathrm{B}^{\prime}, \mathrm{BC}^{\prime} \mathrm{B}^{\prime}, \mathrm{CA}^{\prime} \mathrm{C}^{\prime}$, and $\mathrm{CB}^{\prime} \mathrm{C}^{\prime}$ polymers are the next synthetically possible triblock terpolymers by the linking methodology. Furthermore, a triblock terpolymer of $\mathrm{A}_{1}{ }^{\prime} \mathrm{B}^{\prime} \mathrm{A}_{2}{ }^{\prime}$ type without the use of $\mathrm{A}, \mathrm{B}$, and $\mathrm{C}$, for instance, P $\alpha \mathrm{MS}-b$-P4VP- $b$-poly(4-methoxystyrene), can be synthesized. The $A_{1}{ }^{\prime}$ and $A_{2}{ }^{\prime}$ blocks are the polymer segments obtained from two different monomers categorized as monomer $\mathbf{a}^{\prime}$. A wide variety of functional groups can also be introduced into block polymers by employing functional monomers as $\mathrm{A}^{\prime}, \mathrm{B}^{\prime}$, and/or $\mathrm{C}^{\prime}$ blocks. Thus, the use of $\mathrm{A}^{\prime}, \mathrm{B}^{\prime}$, and $\mathrm{C}^{\prime}$ blocks in the linking methodology will significantly expand the range of available triblock terpolymers.

\subsection{Synthetic Possibility of Other Block Polymers}

The linking methodology could be further extended to the synthesis of an ABCA tetrablock terpolymer of PS- $b$-P2VP- $b$-PMMA- $b$-PS and a special AB diblock copolymer of PMMA- $b$-poly(3-hexylthiophene) (P3HT) containing a conductive rigid rod-like segment. Scheme 10 shows the reaction sequence of the tetrablock terpolymer using three monomers with different reactivities by the same linking methodology. As it was seen, the PS- $b$-P2VP- $b$-PMMA- $b$-PS (ABCA) tetrablock terpolymer was successfully synthesized by the linking reaction of a living triblock terpolymer of PS- $b$-P2VP- $b$-PMMA (ABC) with an $\alpha$-chain-end-PA-functionalized PS (A) at $-40{ }^{\circ} \mathrm{C}$ for $20 \mathrm{~h}$. This success strongly indicates the synthetic possibility of other tetrablock terpolymers and multiblock polymers composed of more than four blocks by means of the linking reaction.

Recent discovery of the quasi-living Grignard metathesis (GRIM) polymerization system made it possible to synthesize well-defined chain-end-functionalized P3HTs with controlled molecular weights $\left(M_{\mathrm{n}}=5-20 \mathrm{~kg} / \mathrm{mol}\right)$ and relatively narrow molecular weight distributions $\left(M_{\mathrm{w}} / M_{\mathrm{n}}<1.2\right)[62-65]$. As illustrated in Scheme 11, an $\omega$-chain-end-formyl-functionalized P3HT was prepared by the GRIM polymerization of $3 \mathrm{HT}$, followed by the Steglich reaction with DMF and $\mathrm{POCl}_{3}$ to change the terminal 
group to a formyl function, reduction with $\mathrm{LiAlH}_{4}$, and esterification with $\alpha$-phenylacrylic acid [66]. A living PMMA $\left(M_{\mathrm{n}}=11.0 \mathrm{~kg} / \mathrm{mol}, M_{\mathrm{w}} / M_{\mathrm{n}}=1.04\right)$ was prepared in the usual manner and reacted with the $\omega$-chain-end-formyl-functionalized P3HT $\left(M_{\mathrm{n}}=4.80 \mathrm{~kg} / \mathrm{mol}, M_{\mathrm{w}} / M_{\mathrm{n}}=1.15\right)$ in THF at $-30{ }^{\circ} \mathrm{C}$ for $24 \mathrm{~h}$. The linking reaction was complete under such conditions to afford a well-defined rod-coil P3HP- $b$-PMMA $\left(M_{\mathrm{n}}=15.0 \mathrm{~kg} / \mathrm{mol}, M_{\mathrm{w}} / M_{\mathrm{n}}=1.08\right)$ having a conductive character. This block copolymer showed an interesting microphase-separated structure at the molecular level, in which the conductive microdomains were arranged at the nano-scale. Thus, if chain-end modification is possible to introduce the PA terminus, any polymer, even via a different polymerization mechanism, can be used in the linking reaction to synthesize the block polymer. This enables the range of synthetically possible block polymers by the linking reaction to be further broadened.

Scheme 10. Synthesis of PS- $b$-P2VP- $b$-PMMA- $b$-PS tetrablock terpolymer.

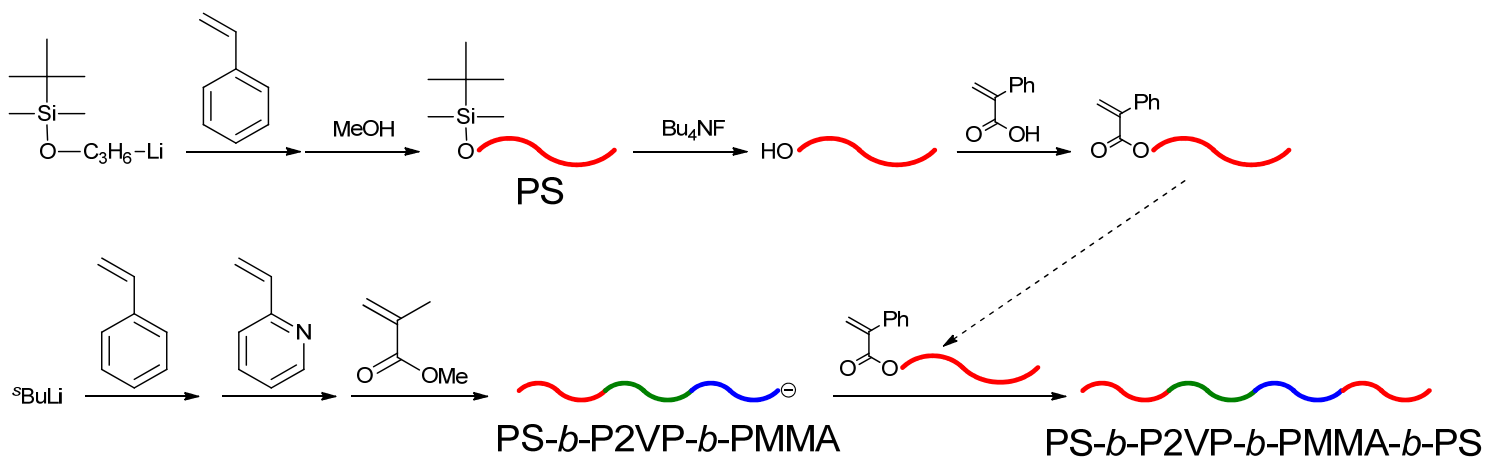

Scheme 11. Synthesis of a rod-coil P3HP-b-PMMA diblock copolymer.
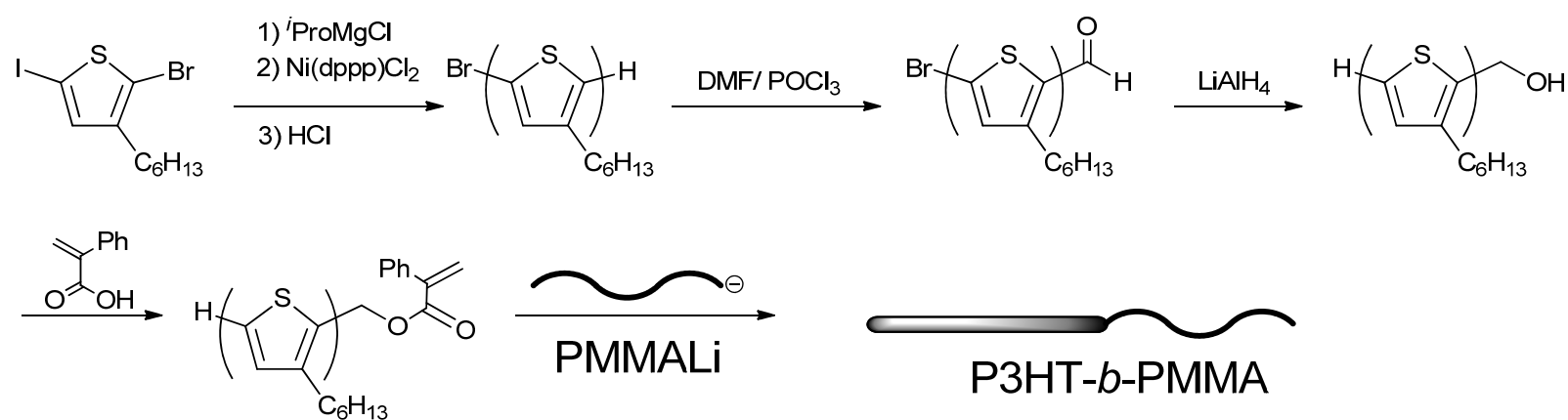

\section{Future Outlook}

Throughout this article, two linking methodologies in conjunction with living anionic polymerization system are introduced for the synthesis of various well-defined triblock polymers, multiblock polymers composed of more than four blocks, and alternate multiblock copolymers, which cannot be synthesized by sequential polymerization. The first linking methodology with a new heterofunctional linking agent, 1, was developed by Hadjichristidis and his coworkers. Since living PDMS is too low in nucleophilicity to initiate the polymerization of most vinyl monomers, which undergo living anionic polymerization, block polymer synthesis by sequential polymerization is very difficult or probably almost impossible. The first developed methodology based on the selective reaction of 1 with living PDMS and a further linking reaction with living anionic polymers or block 
polymers is very useful for the synthesis of multiblock polymers containing PDMS blocks. With this methodology, various well-defined PDMS-containing multiblock polymers even up to the pentablock quintopolymer, PS- $b$-PI- $b$-PDMS- $b$-P'BMA- $b$-P2VP, were successfully synthesized.

The second linking methodology using the PA reaction site was developed by Hirao and his coworkers in order to synthesize a variety of multiblock polymers composed of vinyl polymer blocks. As often mentioned, an $\mathrm{ABC}$ triblock terpolymer is the only synthetically possible triblock terpolymer by sequential polymerization using three monomers with different reactivities, (a) typically styrene, (b) 2VP, and (c) MMA. The success of the second methodology makes it possible to synthesize almost all block polymers. In fact, not only $\mathrm{ACB}(\mathrm{BCA})$ and $\mathrm{BAC}(\mathrm{CAB})$ triblock terpolymers, but also ABA, $\mathrm{ACA}, \mathrm{BAB}, \mathrm{BCB}, \mathrm{CAC}$, and $\mathrm{CBC}$ triblock copolymers as well as $(\mathrm{AB})_{n}$ and $(\mathrm{AC})_{n}$ (and possibly $\left.(\mathrm{BC})_{\mathrm{n}}\right)$ alternate multiblock copolymers were successfully synthesized. The synthesis of special triblock copolymers of $\mathrm{BAB}, \mathrm{CAC}$, and $\mathrm{CBC}$ having molecular asymmetry in both side blocks was also possible. Furthermore, a tetrablock terpolymer of ABCA was synthesized in a similar linking manner. Thus, multiblock polymers in any sequential order and a number of blocks as desired may possibly be synthesized by the linking reaction using the PA reaction site when using $\mathbf{a}, \mathbf{b}$, and $\mathbf{c}$ with different reactivities.

The numbers of synthetically possible block polymer further and greatly increased by using many other monomers listed in Chart 1, in addition to styrene, 2VP, and MMA. In fact, various quite new triblock terpolymers represented as $\mathrm{ABA}^{\prime}, \mathrm{ACA}^{\prime}, \mathrm{CAC}^{\prime}$, and so on, were synthesized for the first time by the linking reaction using three structurally different monomers with two different reactivities. The PS- $b$-P2VP- $b$-P $\alpha$ MS and PMMA- $b$-PS- $b$-P ${ }^{t}$ BMA triblock terpolymers, for instance, are such typical examples. Moreover, a P $\alpha$ MS- $b$-P4VP- $b$-poly(4-methoxystyrene) triblock terpolymer of the $\mathrm{A}_{1}{ }^{\prime} \mathrm{B}^{\prime} \mathrm{A}_{2}{ }^{\prime}$ type could be synthesized. Further importantly, a wide variety of functional groups, such as hydroxyl, amino, formyl, and carboxyl functions, were introduced into the block polymers with the use of functional monomers, also listed in Chart 1.

Thus, it should be mentioned that even now, a huge number of multiblock polymers with any sequential order and any block architecture can be synthesized by developing the linking methodologies introduced in this article. Since the first and second linking methodologies are based on the same concept, the combining of both methodologies may also allow access to a wider variety of multiblock polymers, which cannot be synthesized by any other methods.

It is known that phenyl vinyl sulfoxide [67] and alkyl isocyanate monomers [43-46] undergo living anionic polymerization to result in interesting polymers, poly(4-phenyl vinyl sulfoxide), convertible to conductive rod-like poly(acetylene) and poly(alkyl isocyanate)s with helical conformation. These specialty functional polymers may also be used, at least to a certain extent, in the linking methodology to synthesize block polymers containing blocks with rod-like and helical conformations. One indicative example was introduced in the section 3. Furthermore, the living anionic polymerization of cyclic monomers [68], such as epoxides, cyclic sulfides, lactones, lactides, and even NCA [69], may be applied to the linking methodology, although a new reaction site capable of linking with their living anionic polymers is needed.

The linking methodologies introduced in this article are different from the recently developed methodologies based on Click reactions in terms of the direct use of living anionic polymers in the linking reaction. This is advantageous that one more chain-end modification for linking can be avoided 
and several possible reaction sites capable of linking can be used, taking into consideration about the use of highly reactive living anionic polymers. Moreover, to the best of our experience, the linking reaction can smoothly and efficiently take place among living anionic polymers and chain-end(reaction site)-functionalized polymers with $M_{\mathrm{n}}$ values of several 10,000 g/mol orders. Although the direct comparison in linking efficiency seems difficult, most linking reactions by means of Click reactions so far reported are generally carried out among polymers having $M_{\mathrm{n}}$ values in the range of several 1000 and less than $10,000 \mathrm{~g} / \mathrm{mol}$.

\section{Conflict of Interest}

The authors declare no conflict of interest.

\section{References}

1. Quirk, R.P., IV. Anionic Synthesis of Polymers with Well-Defined Structures. 12. Block Copolymers. In Anionic Polymerization: Principles and Applications; Hsieh, H.L., Quirk, R.P., Eds.; Marcel Dekker: New York, NY, USA, 1996; pp. 307-331.

2. Hamley, W. The Physics of Block Copolymers; Oxford University Press: New York, NY, USA, 1998; 24-220.

3. Park, C.; Yoon, J.; Thomas, E.L. Enabling nanotechnology with self assembled block copolymer patterns. Polymer 2003, 44, 6725-6760.

4. Mori, H.; Müller, A.H.E. New polymeric architectures with (meth)acrylic acid segments. Prog. Polym. Sci. 2003, 28, 1403-1439.

5. Adhikari, R.; Michler, G.H. Influence of molecular architecture on morphology and micromechanical behavior of styrene/butadiene block copolymer systems. Prog. Polym. Sci. 2004, 29, 949-986.

6. Hoeben, F.J.M.; Jonkheijm, P.; Meijer, E.W.; Schenning, A.P.H. About supramolecular assemblies of $\pi$-conjugated systems. Chem. Rev. 2005, 105, 1491-1546.

7. Hadjichristidis, N.; Iatrou, H.; Pitsikalis, M.; Pispas, S.; Avgeropoulos, A. Linear and non-linear triblock terpolymers: Synthesis, self-assembly in selective solvents and in bulk. Prog. Polym. Sci. 2005, 30, 725-782.

8. Abetz, V.; Simon, P.F.W. Phase behavior and morphology of block copolymers. Adv. Polym. Sci. 2005, 189, 125-212.

9. Anderson-Wile, A.M.; Edson, J.B.; Coates, G.W. Living Alkene Polymerization for Polyolefin Architectures. In Complex Macromolecular Architectures: Synthesis, Characterization, and Self-Assembly; Hadjichristidis, N., Hirao, A., Tezuka, Y., Du Prez, Y., Eds.; John Wiley \& Sons (Asia): Singapore, 2011; pp. 267-316.

10. Yu, C.Y.; Turner, M.L. Phenylenevinylene Homopolymers and Block Copolymers via Ring-Opening Metathesis Polymerization. In Complex Macromolecular Architectures: Synthesis, Characterization, and Self-Assembly; Hadjichristidis, N., Hirao, A., Tezuka, Y., Du Prez, Y., Eds.; John Wiley \& Sons (Asia): Singapore, 2011; pp. 377-393. 
11. Higashihara, T.; Ueda, M. Block Copolymers Containing Rod Segments. In Complex Macromolecular Architectures: Synthesis, Characterization, and Self-Assembly; Hadjichristidis, N., Hirao, A., Tezuka, Y., Du Prez, Y., Eds.; John Wiley \& Sons (Asia): Singapore, 2011; pp. 395-429.

12. Iatrou, H.; Pitsikalis, M.; Sakellariou, G.; Hadjichristidis, N. Complex Macromolecular Chimeras. In Complex Macromolecular Architectures: Synthesis, Characterization, and Self-Assembly; Hadjichristidis, N., Hirao, A., Tezuka, Y., Du Prez, Y., Eds.; John Wiley \& Sons (Asia): Singapore, 2011; pp. 461-489.

13. Whittell, G.R.; Gwyther, J.; Rider, D.A.; Manners, I. Self-assembly and Application of Polyferrocenylsilane Block Copolymers. In Complex Macromolecular Architectures: Synthesis, Characterization, and Self-Assembly; Hadjichristidis, N., Hirao, A., Tezuka, Y., Du Prez, Y., Eds.; John Wiley \& Sons (Asia): Singapore, 2011; pp. 493-526.

14. Kuo, C.C.; Liu, C.L.; Chen, W.C. Morphologies and Photophysical Properties of Conjugated Rod-Coil Block Copolymers. In Complex Macromolecular Architectures: Synthesis, Characterization, and Self-Assembly; Hadjichristidis, N., Hirao, A., Tezuka, Y., Du Prez, Y., Eds.; John Wiley \& Sons (Asia): Singapore, 2011; pp. 593-622.

15. Lecommandoux, S. Bulk Self-Assembly of Linear Hybrid Polypeptide-Based Diblock and Triblock Copolymers. In Complex Macromolecular Architectures: Synthesis, Characterization, and Self-Assembly; Hadjichristidis, N., Hirao, A., Tezuka, Y., Du Prez, Y., Eds.; John Wiley \& Sons (Asia): Singapore, 2011; pp. 623-645.

16. Yokoyama, H.; Sugiyama, K. Fluorine-Containing Block Copolymers: Synthesis and Application as a Template for Nanocellular and Porous Structures Using Supercritical Carbon Dioxide. In Complex Macromolecular Architectures: Synthesis, Characterization, and Self-Assembly; Hadjichristidis, N., Hirao, A., Tezuka, Y., Du Prez, Y., Eds.; John Wiley \& Sons (Asia): Singapore, 2011; pp. 717-737.

17. Chavis, M.A.; Schwartz, E.L.; Ober, C.K. Block Copolymer Nanostructured Thin Films for Advanced Patterning. In Complex Macromolecular Architectures: Synthesis, Characterization, and Self-Assembly; Hadjichristidis, N., Hirao, A., Tezuka, Y., Du Prez, Y., Eds.; John Wiley \& Sons (Asia): Singapore, 2011; pp. 763-790.

18. Kahveci, M.U.; Yagci, Y.; Avgeropulos, A.; Tsitsilanis, C. Well-Defined Block Copolymers. In Polymer Science: A Comprehensive Reference; Matyjaszewski, K., Möller, M., Eds.; Elsevier BV: Amsterdam, The Netherlands, 2012; Volume 6, pp. 455-509.

19. Buchmeiser, M.R. Ring-Opening Metathesis Polymerization. In Synthesis of Polymers: New Structures and Methods; Schüter, D., Hawker, C.J., Sakamoto, J., Eds.; Wiley-VCH: Weinheim, Germany, 2012; Volume 2, pp. 547-586.

20. Barner-Kowollik, C.; Blinco, J.P.; Perrier, S. Macromolecular Engineering via RAFT Chemistry: From Sequential to Modular Design. In Synthesis of Polymers: New Structures and Methods; Schüter, D., Hawker, C.J., Sakamoto, J., Eds.; Wiley-VCH: Weinheim, Germany, 2012; Volume 2, pp. 601-626.

21. De, P.; Faust, R. Carbocationic Polymerization. In Synthesis of Polymers: New Structures and Methods; Schüter, D., Hawker, C.J., Sakamoto, J., Eds.; Wiley-VCH: Weinheim, Germany, 2012; Volume 2, pp. 775-817. 
22. Hasegawa, H. Morphologies of Block and Star-Branched Polymers with Three Components. In Complex Macromolecular Architectures: Synthesis, Characterization, and Self-Assembly; Hadjichristidis, N., Hirao, A., Tezuka, Y., Du Prez, Y., Eds.; John Wiley \& Sons (Asia): Singapore, 2011; pp. 569-591.

23. Mogi, Y.; Kotsuji, H.; Kaneko, Y.; Mori, K.; Matsushita, Y.; Noda, I. Preparation and morphology of triblock copolymers of the ABC type. Macromolecules 1992, 25, 5408-5411.

24. Stadler, R.; Austrra, C.; Beckmann, J.; Krappe, U.; Voigt-Martin, I.; Leibler, L. Morphology and thermodynamics of symmetric poly(A-block-B-block-C) triblock copolymers. Macromolecules 1995, 28, 3080-3097.

25. Bates, F.; Fredrickson, G.H. Block copolymers-designer soft materials. Phys. Today 1999, 52, $32-38$.

26. Jiang, S.; Goepfert, A.; Abetz, V. Novel morphologies of block copolymer blends via hydrogen bonding. Macromolecules 2003, 36, 6171-6177.

27. Matsushita, Y. Creation of hierarchically ordered nanophase structures in block polymers having various competing interactions. Macromolecules 2007, 40, 771-776.

28. Nakahama, S.; Hirao, A. Protection and polymerization of functional monomers: Anionic living polymerization of protected monomers. Prog. Polym. Sci. 1990, 15, 299-335.

29. Hirao, A.; Nakahama, S. Anionic living polymerization of monomers with functional silyl groups. Prog. Polym. Sci. 1992, 17, 283-317.

30. Hirao, A.; Nakahama, S. Recent developments in anionic living polymerization. Trends Polym. Sci. 1994, 2, 267-271.

31. Hirao, A.; Loykulnant, S.; Ishizone, T. Recent advance in living anionic polymerization of functionalized styrene derivatives. Prog. Polym. Sci. 2002, 27, 1399-1471.

32. Ishizone, T.; Hirao, A. Anionic Polymerization: Recent Advances. In Synthesis of Polymers: New Structures and Methods; Schüter, D., Hawker, C.J., Sakamoto, J., Eds.; Wiley-VCH: Weinheim, Germany, 2012; Volume 2, pp. 81-134.

33. Ishizone, T.; Sugiyama, K.; Hirao, A. Anionic Polymerization of Protected Functional Monomers. In Polymer Science: A Comprehensive Reference; Matyjaszewski, K., Möller, M., Eds.; Elsevier BV: Amsterdam, The Netherlands, 2012; Volume 3, pp. 591-621.

34. Ishizone, T.; Sugiyama, K.; Sakano, Y.; Mori, H.; Hirao, A.; Nakahama, S. Anionic polymerizations of perfluoroalkyl methacrylates and synthesis of well-defined ABC triblock copolymers of methacrylates containing hydrophilic, hydrophobic, and perfluoroalkyl groups. Polym. J. 1999, 31, 983-988.

35. Tanaka, Y.; Hasegawa, H.; Hashimoto, T.; Ribbe, A.; Sugiyama, K.; Hirao, A.; Nakahama, S. A study of three-phase structures in ABC triblock copolymers. Polym. J. 1999, 31, 989-994.

36. Giebeler, E.; Stadler, R. ABC triblock polyampholytes containing a neutral hydrophobic block, a polyacid, and a polybase. Macromol. Chem. Phys. 1997, 198, 3815-3825.

37. Ludwigs, S.; Böker, A.; Abetz, V.; Müller, A.H.E.; Krausch, G. Phase behavior of linear polystyrene-block-poly(2-vinylpyridine)-block-poly(tert-butyl methacrylate) triblock terpolymers. Polymer 2003, 44, 6815-6823.

38. Goldacker, T.; Abetz, V.; Stadler, R.; Erukhimovich, I.; Leibler, L. Non-centrosymmetric superlattices in block copolymer blends. Nature 1999, 398, 137-139. 
39. Wolf, A.; Walther, A.; Müller, A.H.E. Janus triad: Three types of nonspherical, nanoscale janus particles from one single triblock terpolymer. Macromolecules 2011, 44, 9221-9229.

40. Bieringer, R.; Abetz, V.; Müller, A.H.E. Triblock copolyampholytes from 5-( $N, N$-dimethylamino) isoprene, styrene, and methacrylic acid: Synthesis and solution properties. Eur. Phys. J. E 2001, 5, 5-12.

41. Betthausen, E.; Drechsler, M.; Foertsch, M.; Schacher, F.H.; Müller, A.H.E. Dual stimuli-responsive multicompartment micelles from triblock terpolymers with tunable hydrophilicity. Soft Matter 2011, 7, 8880-8891.

42. Böker, A.; Müller, A.H.E.; Krausch, G. Nanoscopic surface patterns from functional ABC triblock copolymers. Macromolecules 2001, 34, 7477-7488.

43. Ekizoglou, N.; Hadjichristidis, N. Synthesis of model linear tetrablock quaterpolymers and pentablock quintopolymers of ethylene oxide. J. Polym. Sci. A 2002, 1, 2166-2170.

44. Lee, J.S.; Ryu, S.W. Anionic living polymerization of 3-(Triethoxysilyl)propyl isocyanate. Macromolecules 1999, 32, 2085-2087.

45. Shin, Y.D.; Kim, S.Y.; Ahn, J.H.; Lee, J.S. Synthesis of poly(n-hexyl isocyanate) by controlled anionic polymerization in the presence of $\mathrm{NaBPh} 4$. Macromolecules 2001, 34, 2408-2410.

46. Ahn, J.H.; Shin, Y.D.; Nath, G.Y.; Park, S.Y.; Rahman, M.S.; Samal, S.; Lee, J.S. Unprecedented control over polymerization of n-Hexyl isocyanate using an anionic initiator having synchronized function of chain-end protection. J. Am. Chem. Soc. 2005, 127, 4132-4133.

47. Vazaios, A.; Pitsikalis, M.; Hadjichristidis, N. Triblock copolymers and pentablock terpolymers of n-hexyl isocyanate with styrene and isoprene: Synthesis, characterization, and thermal properties. J. Polym. Sci. A 2003, 41, 3094-3102.

48. Bellas, V.; Iatrou, H.; Hadjichristidis, N. Controlled anionic polymerization of hexamethylcyclotrisiloxane. Model linear and miktoarm star co- and terpolymers of dimethylsiloxane with styrene and isoprene. Macromolecules 2000, 33, 6993-6997.

49. Nagay, N.; Kucukyavuz, Z.; Kucukyavuz, S. Anionic synthesis and characterization of poly(4-vinylpyridine)-poly(dimethylsiloxane) block copolymers. Polym. Int. 1993, 32, 93-96.

50. Bellas, V.; Iatrou, H.; Pitsinos, E.N.; Hadjichristidis, N. Heterofunctional linking agents for the synthesis of well-defined block copolymers of dimethylsiloxane and tert-Butyl methacrylate or 2-vinylpyridine. Macromolecules 2001, 34, 5376-5378.

51. Fragouli, P.G.; Iatrou, H.; Hadjichristidis, N. Synthesis and characterization of linear tetra block quarter polymers of styrene, isoprene, dimethylsiloxane, and 2-vinylpyridine. J. Polym. Sci. A 2004, 42, 514-519.

52. Fragouli, P.G.; Iatrou, H.; Lohse, D.J.; Hadjichristidis, N. Linear pentablock quintopolymers (1-SIDMV) with five incompatible blocks: Polystyrene, polyisoprene-1,4, poly(dimethylsiloxane), poly(tert-butyl methacrylate), and poly(2-vinylpyridine). J. Polym. Sci. A 2008, 46, 3938-3946.

53. Hirao, A.; Murano, K.; Oie, T.; Uematsu, M.; Goseki, R.; Matsuo, Y. Chain-end- and in-chain-functionalized $\mathrm{AB}$ diblock copolymers as key building blocks in the synthesis of well-defined architectural polymers. Polym. Chem. 2011, 2, 1219-1233. 
54. Hirano, T.; Yoo, H.S.; Ozama, Y.; Abou, E.M.A.; Sugiyama, K.; Hirao, A. Precise synthesis of novel ferrocene-based star-branched polymers by using specially designed 1,1-diphenylethylene derivatives in conjunction with living anionic polymerization. J. Inorg. Organomet. Polym. Mater. 2010, 20, 445-456.

55. Hirao, A.; Murano, K.; Abou, E.M.A.; Uematsu, M.; Ito, S.; Goseki, R.; Ishizone, T. General and facile approach to exact graft copolymers by iterative methodology using living anionic in-chain-functionalized AB diblock copolymers as key building blocks. Macromolecules 2011, 44, 3302-3311.

56. Hirao, A.; Uematsu, M.; Kurokawa, R.; Ishizone, T.; Sugiyama, K. Facile synthetic approach to exact graft (co)polymers and double-tailed polystyrene: Linking reaction of living anionic polymers with specially designed in-chain-multifunctionalized polystyrenes. Macromolecules 2011, 44, 5638-5649.

57. Yoo, H.S.; Watanabe, T.; Matsunaga, Y.; Hirao, A. Precise synthesis of dendrimer-like star-branched poly(tert-butyl methacrylate)s and their block copolymers by a methodology combining $\alpha$-terminal-functionalized living anionic polymers with a specially designed linking reaction in an iterative fashion. Macromolecules 2012, 45, 100-112.

58. Ito, S.; Goseki, R.; Senda, S.; Hirao, A. Precise synthesis of miktoarm star polymers by using a new dual-functionalized 1,1-diphenylethylene derivative in conjunction with living anionic polymerization system. Macromolecules 2012, 45, 4997-5011.

59. Hirao, A.; Matsuo, Y.; Oie, T.; Goseki, R.; Ishizone, T.; Sugiyama, K.; Gröschel, A.H.; Müller, A.H.E. Facile synthesis of triblock co- and terpolymers of styrene, 2-vinylpyridine, and methyl methacrylate by a new methodology combining living anionic diblock copolymers with a specially designed linking reaction. Macromolecules 2011, 44, 6345-6355.

60. Matsuo, Y.; Oie, T.; Goseki, R.; Ishizone, T.; Sugiyama, K.; Hirao, A. Precise synthesis of new triblock co- and terpolymers by a methodology combining living anionic polymers with a specially designed linking reaction. Macromol. Symp. 2013, 323, 26-36.

61. Sugiyama, K.; Oie, T.; Abou, E.M.A.; Hirao, A. Synthesis of well-defined (AB)n multiblock copolymers composed of polystyrene and poly(methyl methacrylate) segments using specially designed living AB diblock copolymer anion. Macromolecules 2010, 43, 1403-1410.

62. Yokoyama, A.; Miyakoshi, R.; Yokozawa, T. Chain-growth polymerization for poly(3-hexylthiophene) with a defined molecular weight and a low polydispersity. Macromolecules 2004, 37, 1169-1171.

63. Miyakoshi, R.; Yokoyama, A.; Yokozawa, T. Catalyst-transfer polycondensation. Mechanism of Ni-catalyzed chain-growth polymerization leading to well-defined poly(3-hexylthiophene). J. Am. Chem. Soc. 2005, 127, 17542-17547.

64. Sheina, E.E.; Liu, J.; Iovu, M.C.; Laird, D.W.; McCullough, R.D. Chain growth mechanism for regioregular nickel-initiated cross-coupling polymerizations. Macromolecules 2004, 37, 3526-3528.

65. Iovu, M.C.; Sheina, E.E.; Gil, R.R.; McCullough, R.D. Experimental evidence for the quasi-"living" nature of the grignard metathesis method for the synthesis of regioregular poly(3-alkylthiophenes). Macromolecules 2005, 38, 8649-8656.

66. Moon, H.C.; Anthonysamy, A.; Kim, J.K.; Hirao, A. Facile synthetic route for well-defined poly(3-hexylthiophene)-block-poly(methyl methacrylate) copolymer by anionic coupling reaction. Macromolecules 2011, 44, 1894-1899. 
67. Kanga, R.S.; Hogen-Esch, T.E.; Randrianalimanana, E.; Soum, A.; Fontanille, M. Studies of the anionic polymerization of phenylvinylsulfoxide and its copolymer with styrene. Macromolecules 1990, 23, 4235-4240.

68. Kamber, N.E.; Jeong, W.; Waymouth, R.M.; Pratt, R.C.; Lohmeijer, B.G.G.; Hedrick, J.L. Organocatalytic ring-opening polymerization. Chem. Rev. 2007, 107, 5813-5840.

69. Hadjichristidis, N.; Iatrou, H.; Pitsikalis, M.; Sakellariou, G. Synthesis of well-defined polypeptide-based materials via the ring-opening polymerization of $\alpha$-Amino acid $\mathrm{N}$-carboxyanhydrides. Chem. Rev. 2009, 109, 5528-5578.

(C) 2013 by the authors; licensee MDPI, Basel, Switzerland. This article is an open access article distributed under the terms and conditions of the Creative Commons Attribution license (http://creativecommons.org/licenses/by/3.0/). 